\section{Assessing Simple Policy Rules: A View from a Complete Macroeconomic Model}

\author{
Eric M. Leeper and Tao Zha
}

\section{INTRODUCTION}

P olicy analysts must make tough choices: should they use a model where the economic behavior is stripped down and easy to understand, but whose fit to data is crude, or should they use a model whose fit and forecast performance are good, but with economic behavior that is not very detailed? The need to tell tidy stories frequently dominates the desire to fit data. This is not a choice between "simple" and "complex," though it is sometimes couched as such. A model must be simple if it's to be understood. It must be understood if it's to inform policy debates. Unfortunately, we understand models on a qualitative level, while we use them for policy analysis on a quantitative level. Tensions arise in moving from qualitative discussion to quantitative prediction.

The tensions are well illustrated by two popular approaches to empirical analysis of monetary policy: the New Keynesian (NK) and the identified vector autoregression (VAR) approaches. Stylized models of private behavior coupled with simple rules describing policy behavior characterize NK work. VARs consist of minimally identified dynamic descriptions of private behavior coupled with a detailed rule for policy behavior. ${ }^{1}$

The choice between the two approaches wouldn't matter if they offered the same interpretations of policy behavior and the same predictions for the impacts of changes in policy. But they do not.

Much of the appeal of NK models derives from their simplicity. ${ }^{2}$ Implications of the model are easy to communicate and have rapidly become a standard framework for discussing monetary policy. Simple

Eric M. Leeper is a professor of economics at Indiana University, Department of Economics, Bloomington, Indiana, and Tao Zha is a research officer at the Federal Reserve Bank of Atlanta. The authors thank Dan Waggoner for helpful discussions. The views expressed in this paper are solely the responsibility of the authors and should not be interpreted as reflecting the views of the Federal Reserve Bank of Atlanta or the Board of Governors of the Federal Reserve System. models often produce stark conclusions. NK models deliver the stark conclusion that good monetary policy calls for the central bank to adjust the nominal interest rate more than one-for-one with inflation. Some authors argue that Federal Reserve behavior under Alan Greenspan is superior-nearly optimal, by some calculations - to Fed behavior before Paul Volcker became chair in $1979 .{ }^{3} \mathrm{NK}$ researchers base their case that policy has improved on estimates of the parameter that determines how much the Fed adjusts the federal funds rate when inflation changes. Estimates of a stronger response to inflation after 1979 than before 1979 underlie the NK case. An unstable policy rule is the linchpin in the NK case that monetary policy has improved. VARs, in contrast, tend to find little evidence of either important instability in policy parameters or instability in the dynamic impacts of exogenous shifts in policy. 4

Simplicity also makes NK models vulnerable. In simple models, behavioral relationships are tightly circumscribed and sparsely parameterized. As a consequence, each parameter carries a hefty share of the model's implications: the value of a single parameter can mean the difference between inferring that policy was stabilizing or destabilizing. Because dynamics are carefully pruned, there is a great deal of simultaneous behavior. It is no surprise that this environment breeds identification problems. ${ }^{5}$ Taken together, simplicity and simultaneity make it very difficult to nail down estimates of critical parameters. Despite this difficulty, singleequation estimation techniques constitute the bulk of the empirical work in the NK literature.

1 NK work is associated with Rotemberg and Woodford $(1997,1999)$, Clarida, Gali, and Gertler (1999, 2000), and McCallum and Nelson (1999); and identified VARs are associated with Leeper, Sims, and Zha (1996), Christiano, Eichenbaum, and Evans (1999), and Bernanke and Mihov (1998). A third approach combines simple Taylor-type rules with large econometric models of the economy as in Bryant, Hooper, and Mann (1993), Taylor (1993b), and Levin, Wieland, and Williams (1999).

2 At the conference, a semantic debate took place concerning whether the class of models we have in mind are "New Keynesian." Nothing substantive rests on the terminology. We adopted the term from Clarida, Gali, and Gertler (1999) who labeled the literature "New Keynesian."

3 See, for example, Rotemberg and Woodford (1999) or Gali, Lopez-Salido, and Valles (2000).

4 For example, Bernanke and Mihov (1998), Sims (1999), Leeper and Zha (2001), or Hanson (2000b).

5 NK models are not unique in this regard. Virtually all dynamic stochastic general equilibrium models suffer from the kind of identification problems that concern us (see Canova and Pina, 2000). 
Ironically, Taylor's (1993b) econometric modeling is the genesis for much of the recent NK work with simple policy rules. Identified VARs share with Taylor's analyses an emphasis on the economic system, rather than on single behavioral relationships. In VARs, behavioral relationships are loosely consistent with theory. Dynamics are intricate, typically unrestricted, and difficult to interpret. This makes the output of VARs hard to communicate, and the models often get treated as black boxes. Simultaneity is kept to a minimum: some of the most widely cited VAR models contain none at all. These blunt identifying assumptions, though controversial, can produce robust results. Rarely does instability of a single VAR parameter carry important qualitative implications.

The two approaches share the objective of explaining post-World War II U.S. data. Identifying assumptions, which are what link economic behavior to economic data, sharply distinguish NK and VAR approaches. We pursue that distinction to explore the identification problems that plague any attempt to tease policy behavior out of the tangle of dynamic correlations in macro time series. We take the view that NK models are restricted VARs. Dynamic optimizing behavior generates both linear and cross-equation restrictions. The latter group typically arises to ensure that expectations are rational and consistent with the model's predictions.

In Section II we use an off-the-shelf NK model to obtain identifying restrictions in a three-variable model. We argue that identification problems pervade the model. Calibration offers one solution to these problems. For example, calibrating key private parameters or policy parameters can deliver economically sensible system estimates.

In those models it can be misleading to base inferences about the effects of policy solely on estimated policy parameters. Section III displays models that are stable despite the fact that policy parameters do not satisfy the NK criterion for "stabilizing" policy.

Some of the NK models' simplicity stems from their position on money: it's irrelevant. Money plays no role in the transmission of monetary policy, in the setting of monetary policy, or in the formation of expectations about policy. The monetary sector is a sideshow. Section IV introduces money. Although this creates some new identification challenges, we argue that interpretations of historical policy behavior can change dramatically once money is reintroduced into the analysis. Estimates in that section rely on identifying assumptions that separate the behavior of money demanders from the behavior of the monetary authority. Our results underscore, however, that understandings of behavior can change drastically when one moves away from relying on reduced-form correlations.

Section V puts a sharp point on the tradeoff between simplicity and robustness of inferences. The identified VARs that we report in that section display remarkable stability across subperiods in the postwar data. The stability implies there may not have been important changes in the dynamic responses of the economy to exogenous shifts in policy, raising doubts about the premise of the NK conclusion of superior policy performance in the past 20 years.

Policy may, in fact, have improved over time. But New Keynesians do not make the case.

Some authors argue that because the behavioral equations in NK models emerge from optimization, it is reasonable to treat them as invariant to policy (Rotemberg and Woodford, 1997, and Woodford, 1999b). Similar claims cannot be made for equations in identified VARs. Instead, building on Sims (1987), Leeper and Zha (2001) contend that VARs are linear approximations to an underlying nonlinear model and that, for many practical policy questions, the linear approximations may be quite accurate. We shall not pursue this topic further here; rather, we accept that, for the class of policy interventions we think best characterizes routine Federal Open Market Committee (FOMC) analysis, both approaches estimate private behavioral equations that are virtually invariant.

\section{A CANONICAL NEW KEYNESIAN MODEL}

In this section we lay out a slight variant of the stylized NK model that forms the basis of the monetary policy analyses in Clarida, Gali, and Gertler (1999, 2000), Rotemberg and Woodford (1997, 1999), Woodford (1999a, 1999b), and elsewhere. Under certain parameterizations, the model specializes to Taylor's (1999b) reduced-form model. The empirical results in this section relate to Taylor's version of the model estimated with U.S. data over the period from 1959:Q1 to 2000:Q2.

\section{The Theoretical Model}

Because the micro foundations of the model are well known, we shall simply write down the relevant log-linearized equations. 
The generalized IS equation is 6

$$
\text { (1) IS: } \begin{aligned}
x_{t} & =-\frac{1}{\sigma}\left[i_{t}-E_{t}\left(p_{t+1}-p_{t}\right)-r\right] \\
& +\kappa \theta x_{t-1}+\kappa(1-\theta) E_{t} x_{t+1}+\varepsilon_{t}^{I S} ;
\end{aligned}
$$

and the aggregate supply (AS) or price setting equation is

(2) AS: $p_{t}-p_{t-1}=\lambda_{0} x_{t}+\lambda_{1} x_{t-1}$

$$
\begin{aligned}
& +\psi\left(p_{t-1}-p_{t-2}\right) \\
& +(1-\psi) \beta E_{t}\left(p_{t+1}-p_{t}\right)+\varepsilon_{t}^{A S},
\end{aligned}
$$

where $x$ is the "output gap," defined as actual output minus potential output:

$$
x_{t}=y_{t}-y_{t}^{p} .
$$

Here, $i$ is the nominal interest rate, which is set by the monetary authority; $p$ is the aggregate price level and $p_{t}-p_{t-1}$ is the inflation rate at $t^{7} ; \varepsilon^{I S}$ is an exogenous process reflecting non-monetary policy sources of aggregate demand; $1 / \sigma$ is the intertemporal elasticity of substitution; $r$ is the steady state real interest rate; $\kappa$ is an indicator function equal to 0 or $1 ; \theta$ and $\psi$ lie on the unit interval; $\varepsilon^{A S}$ is an exogenous process reflecting deviations from the condition that real marginal cost and the output gap are proportional; $\beta$ is the discount factor. The expectation $E_{t}$ is taken with respect to an information set that contains all variables dated $t$ and earlier.

As written in equations (1) and (2), we allow for the possibility of both forward- and backwardlooking behavior in the IS and AS relationships. The parameters $\theta$ and $\psi$ determine the extent to which behavior looks forward and backward. We are less concerned with whether backward-looking behavior can be sensibly rationalized in an optimizing framework than we are with extracting the model's implications for empirical work. To that end, it is desirable to work with a flexibly parameterized model.

Complete the model with the monetary policy (MP) rule

(3) $\mathrm{MP}$

$$
\begin{aligned}
i_{t} & =\gamma_{0}+\gamma_{\pi 1}\left[\left(p_{t}-p_{t-1}\right)-\bar{\pi}\right] \\
& +\gamma_{\pi 2}\left[\left(p_{t-1}-p_{t-2}\right)-\bar{\pi}\right]+\gamma_{x 1} x_{t}+\gamma_{x 2} x_{t-1} \\
& +\gamma_{m 1}\left[\left(M_{t}-M_{t-1}\right)-\bar{\mu}\right]+\omega i_{t-1}+\varepsilon_{t}^{M P}
\end{aligned}
$$

where $\omega$ is a parameter that allows for partial adjustment to the target interest rate and determines the degree of interest rate smoothing and $\varepsilon^{M P}$ is a policy disturbance; $\gamma_{\pi 1}$ describes how policy responds to inflation and is the parameter that receives the most attention in the NK literature. $\bar{\pi}$ and $\bar{\mu}$ are target levels for inflation and money growth. This rule represents a substantial generalization of the class of rules typically considered in NK research, as it allows policy choice to depend on the lagged inflation rate and output gap, as well as on current and past money growth. ${ }^{8}$ The rule that Taylor (1993a, 1999a, 1999b) employs, and is now nearly standard equipment in an NK model, sets $i$ solely as a function of the current inflation rate and output gap:

(4)

$$
\begin{aligned}
i_{t} & =\gamma_{0}+\gamma_{\pi 1}\left[\left(p_{t}-p_{t-1}\right)-\bar{\pi}\right] \\
& +\gamma_{x 1} x_{t}+\varepsilon_{t}^{M P} .
\end{aligned}
$$

The two exogenous processes associated with private behavior are $\varepsilon_{t}^{I S}$ and $\varepsilon_{t}^{A S}$, and $\varepsilon_{t}^{M P}$ is the exogenous part of policy behavior.

\section{Potential Identification Problems}

Nearly all the NK papers assume certain values for the private parameters in equations (1) and (2). They then estimate the policy parameters using ordinary least squares or instrumental variables methods or they impose particular policy parameters. Suppose instead that the reduced form - or solved-out version - of equations (1), (2), and (3) were to be estimated simultaneously. Although the reduced form confounds private parameters and policy parameters, we may work with it as long as we do not intend to change policy parameters while holding fixed the reduced-form parameters in the non-policy equations. We can even solve the model numerically, noting, where possible, the linear restrictions the model implies and then imposing those restrictions on our estimation. In this procedure we concentrate on restrictions on contemporaneous interactions among variables, which are the most common identifying restrictions used in empirical work. Because cross-equation restrictions are often at odds with data, we limit ourselves to the linear restrictions that theory implies.

6 Although, strictly speaking, IS involves output rather than the output gap, in equation (1) we follow the convention in the NK literature.

7 In the empirical work below, we convert this to the annual rate $4\left(p_{t}-p_{t-1}\right)$. To avoid notational clutter, we leave the conversion out of the theoretical expressions.

8 Papers by Clarida, Gali, and Gertler (2000) and Bernanke and Woodford (1997) also include policy responses to expected inflation and output. This makes little difference for our purposes. 
Inspection of the three equations of the model suggests the potential for several identification problems to arise. First, both IS and policy link the current nominal rate to inflation and the output gap. If inflation is close to a random walk, then both equations involve $\left(x_{t}, \pi_{t}, i_{t}\right)$ and without additional restrictions they cannot be distinguished. This is a critical problem, as it potentially confounds the impact of monetary policy with other sources of disturbance to aggregate demand, causing misleading interpretations of the role of monetary policy.

Taylor (1999b) resolves the identification problem by considering the model that emerges when $\kappa=0, \lambda_{0}=0$, and $\psi=1$. In that case, the reducedform expression for IS makes $x_{t}=a\left(i_{t}-\pi_{t}-r\right)+\xi_{t}$, for some coefficient $a$, producing an additional restriction that separates IS from monetary policy. ${ }^{9}$ If, in contrast to Taylor's specification, the IS curve is dynamic $(\kappa=1, \theta \in[0,1))$, then Taylor's additional restriction does not hold generally, and nothing distinguishes the reduced forms for IS and policy.

One way to separate IS and MP is to adopt the approach taken in some of the identified VAR literature and advocated by McCallum (1999) in NK models: an operational rule cannot make policy choice depend on variables the Fed does not observe contemporaneously. Because the Fed does not observe inflation and output contemporaneously, we might posit the rule

(5) MP (Taylor lagged): $i_{t}=\gamma_{0}+\gamma_{\pi 2}\left[\left(p_{t-1}-p_{t-2}\right)-\bar{\pi}\right]$

$$
+\gamma_{x 2} x_{t-1}+\varepsilon_{t}^{M P} \text {. }
$$

This rule equates the surprise in the federal funds rate, given past inflation and output, to the exogenous disturbance in monetary policy. Unfortunately, it is well documented that this identification can generate empirical anomalies; a prominent anomaly is that an exogenous monetary contraction raises the funds rate, lowers output, and raises the inflation rate (see, for example, Gordon and Leeper, 1994).

Although it is no longer fashionable to include money in models of monetary policy, the Fed does observe growth rates of various monetary aggregates contemporaneously. And for much of the postwar period the Fed established target growth rates for aggregates. These targets have been pursued with varying degrees of vigilance over the years because, when velocity is fairly predictable, money growth can be informative about future inflation. Adding current money growth to the policy rule in equation (5) produces
(6) MP (with money): $i_{t}=\gamma_{0}+\gamma_{m 1}\left[\left(M_{t}-M_{t-1}\right)-\bar{\mu}\right]$

$$
\begin{aligned}
& +\gamma_{\pi 2}\left[\left(p_{t-1}-p_{t-2}\right)-\bar{\pi}\right] \\
& +\gamma_{x 2} x_{t-1}+\varepsilon_{t}^{M P} .
\end{aligned}
$$

This specification is close to the rule that Ireland (2000) estimates in an NK model. A policy rule like equation (6) carries two important implications. First, money is no longer an appendage to the NK model. Now interaction of supply and demand in the money market determines the money stock and the nominal interest rate simultaneously. This raises the tricky problem of separating money demand and monetary policy. Second, the dynamic IS and AS relationships imply that current inflation and output depend on the entire expected future path of policy. If money enters the policy equation, then it plays a role in forming expectations of policy. The reduced forms for IS and AS now must include the current money stock.

The presence of money in the IS equation raises a new identification problem. Now both IS and money demand include output, the price level, the nominal interest rate, and the money stock. Without further restrictions, IS and money demand are indistinguishable. Homogeneity restrictions play a prominent role in money demand regressions; in fact, the money demand relationship is usually written in terms of the demand for real money balances, reflecting one homogeneity restriction. Another restriction, which many general equilibrium models of money demand imply, is unitary income elasticity. Some VAR work has found it necessary to impose both homogeneity restrictions to model the money market (e.g., Cushman and Zha, 1997).

\section{Estimated Models}

We now illustrate some of these identification problems with estimated models. The reduced form for the NK model with three endogenous variables can be written as

$$
X_{t}^{\prime} A_{0}=C+X_{t-1}^{\prime} A_{1}+X_{t-2}^{\prime} A_{2}+\varepsilon_{t}^{\prime},
$$

where $X_{t}=\left(y_{t}, p_{t}, i_{t}, y_{t}^{p}\right)^{\prime}, C$ is a vector of intercept terms, and $\varepsilon_{t}=\left(\varepsilon_{t}^{I S}, \varepsilon_{t}^{A S}, \varepsilon_{t}^{M P}, \varepsilon_{t}^{y p}\right)^{\prime} .{ }^{10}$ We take the

\footnotetext{
9 In this case, $\pi_{t}=\lambda_{1} x_{t-1}+\pi_{t-1}$, so the IS relationship implies $a=-1 /$ $\sigma\left(1-\lambda_{1}\right)$.

${ }^{10}$ We impose restrictions to express equations in terms of inflation or the output gap.
} 
exogenous disturbances to be i.i.d. with $\varepsilon_{t} \sim N,(0, I)$. In the estimation, we follow tradition and treat potential output, $y^{p}$, as exogenous and estimate an AR(1) process for it. Adding $y^{p}$ to the model in an exogenous block alters the order condition substantially: it buys us three zero restrictions while adding only one free parameter. Most NK work, however, includes the gap, rather than $y$ and $y^{p}$ separately. To keep in the spirit of that work, we assess the order condition as if we estimated the model in terms of $(x, p, i)$.

All data are quarterly and all but the interest rate are seasonally adjusted. The estimation period in this section runs from 1959:Q1 to 2000:Q2; $y$ is real gross domestic product (GDP) (chained 1996 dollars), $p$ is the personal consumption expenditures deflator (chained 1996 dollars), $i$ is the federal funds rate, $y^{p}$ is the Congressional Budget Office's measure of potential GDP (chained 1996 dollars). We choose to estimate data in terms of levels, rather than growth rates, in order to connect the work more closely to the identified VAR literature. We impose all the linear restrictions implied by the NK model and execute maximum likelihood estimation. ${ }^{11}$ All variables are logged except the funds rate, which is a percentage.

In the models reported below we display both the estimated parameters and the impulse response functions computed from

$$
X_{t}=B(L) \varepsilon_{t},
$$

where $B(L)=\left(A_{0}{ }^{\prime}-A_{1}{ }^{\prime} L-A_{2}{ }^{\prime} L^{2}\right)^{-1}$.

Because many of our points are logical, illustrating the nature of identification problems, rather than statistical, we do not report standard errors or error bands for most of the estimated models.

Taylor's (1999b) Model. Taylor's model is described by

$$
\begin{array}{ll}
\text { IS: } & x_{t}=-\frac{1}{\sigma}\left(i_{t}-\pi_{t}-r\right)+\varepsilon_{t}^{I S} \\
\text { (9) } \mathrm{AS}: & \pi_{t}=\lambda_{1} x_{t-1}+\pi_{t-1}+\varepsilon_{t}^{A S} \\
\mathrm{MP}: & i_{t}=\gamma_{0}+\gamma_{\pi 1} \pi_{t}+\gamma_{x 1} x_{t}+\varepsilon_{t}^{M P},
\end{array}
$$

where $\pi_{t}=p_{t}-p_{t-1}$ is the inflation rate. In this model, $\pi_{t}$ is inertial or predetermined, while $x_{t}$ and $i_{t}$ are determined simultaneously. Based on restrictions on $A_{0}$ alone, the model is not identified unless some additional restriction is imposed. Taylor imposes that the coefficients on the nominal rate and inflation in the IS equation are equal and of opposite sign. ${ }^{12}$ Imposing that restriction yields the estimates ${ }^{13}$ :

$$
\begin{aligned}
& x_{t}=0.795\left[i_{t}-\left(p_{t}-p_{t-1}\right)\right]-0.024 \\
& p_{t}-p_{t-1}=0.077 x_{t-1}+\left(p_{t-1}-p_{t-2}\right) \\
& i_{t}=0.820\left(p_{t}-p_{t-1}\right)-0.597 x_{t}+0.032 .
\end{aligned}
$$

With the exception of the AS relationship, none of these parameters is reasonable. IS and MP relationships are confounded: the pattern of coefficients in IS makes more sense as a policy rule, and the pattern of coefficients in the policy equation makes more sense as an IS curve. Figure 1 confirms this interpretation. ${ }^{14}$ The shock identified as IS raises the funds rate and lowers output (although only slightly), while the shock identified as MP raises output, the price level, and the funds rate. The latter is reasonable when interpreted as an endogenous response of policy to higher output and inflation; it is unreasonable when interpreted as an exogenous monetary policy contraction.

Without further restrictions, there appears to be no way to separate the two components of aggregate demand in the model. We turn now to two alternative solutions to this problem.

Calibration as Identification. Perhaps the most popular solution to identification problems is to impose parameter values obtained from other data sets or previous research. While this approach gained popularity initially in the real business cycle literature, its popularity has carried over to research using NK models. We show that transporting parameters from other studies certainly can solve the identification problems inherent in separating IS from MP. First we impose the intertemporal elasticity of substitution, $1 / \sigma=2$, which is within the range of values used in the literature, ${ }^{15}$ and freely

11 First we obtain maximum likelihood estimates of $A_{0}$; then we obtain estimates of $\left(A_{1}, A_{2}, C\right)$, conditional on the MLE of $A_{0}$.

${ }^{12}$ In Taylor's model, the current output gap is excluded from AS. This exclusion restriction is necessary for identification from restrictions on $A_{0}$ alone. Without it, the model is underidentified for two reasons: because it adds the coefficient on $x_{t}$ in AS and because, if $x_{t}$ enters AS, then the restriction on IS that the coefficients on $i$ and $\pi$ be equal and of opposite sign no longer holds. See footnote 9.

${ }^{13}$ The process for potential output is estimated to be $y_{t}^{p}=0.0297+0.998$ $y_{t-1}^{p}$

14 All figures depict impulse responses that have been multiplied by 100 .

15 Rotemberg and Woodford (1997) estimate $\sigma=0.16$, producing an IS interest elasticity of -6.25 , while McCallum and Nelson (1999) estimate $\sigma=4.93$, making the interest elasticity -0.20 . Clarida, Gali, and Gertler (2000) and Gali, Lopez-Salido, and Valles (2000) calibrate their models to $\log$ preferences, so $\sigma=1$. 


\section{Figure 1}

Confounding IS and MP in Taylor's Model

IS
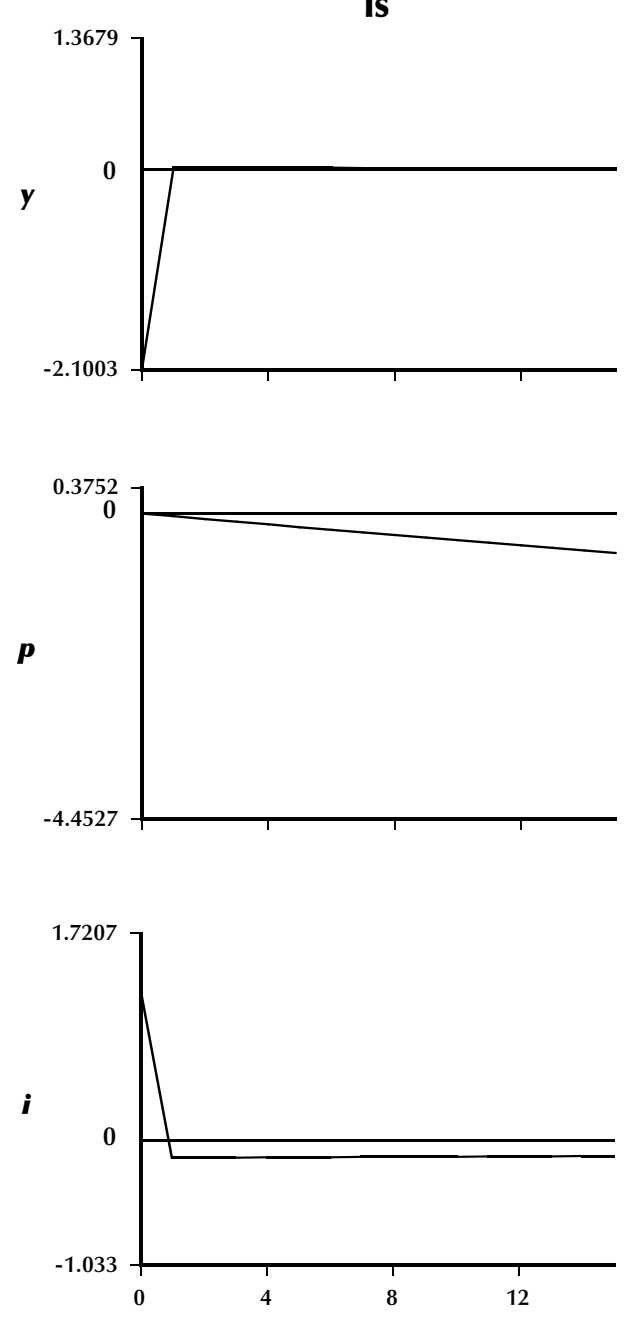

AS
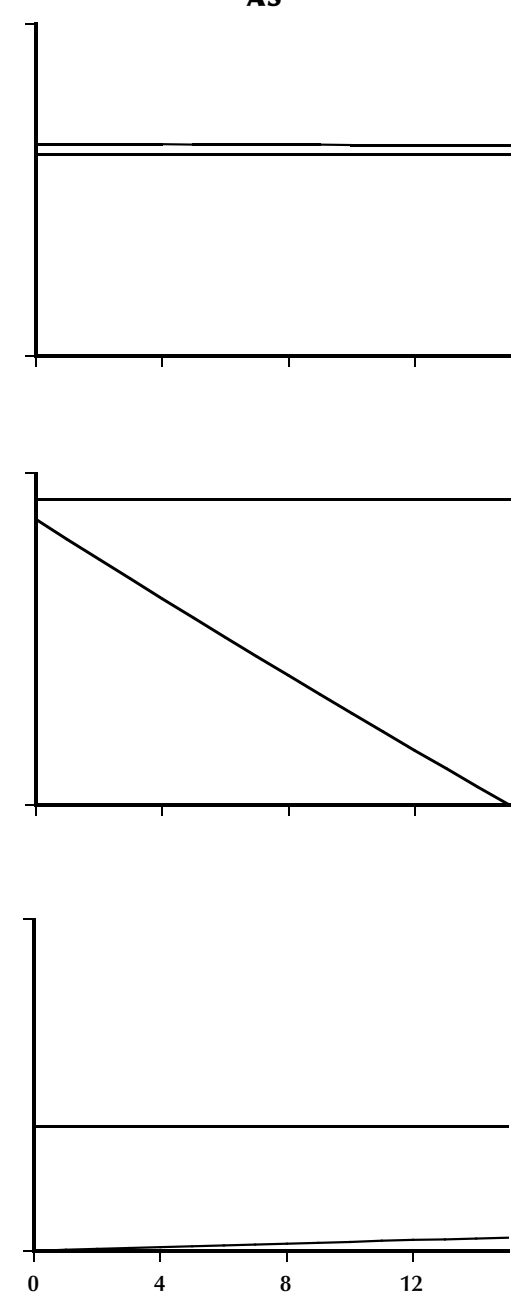

MP
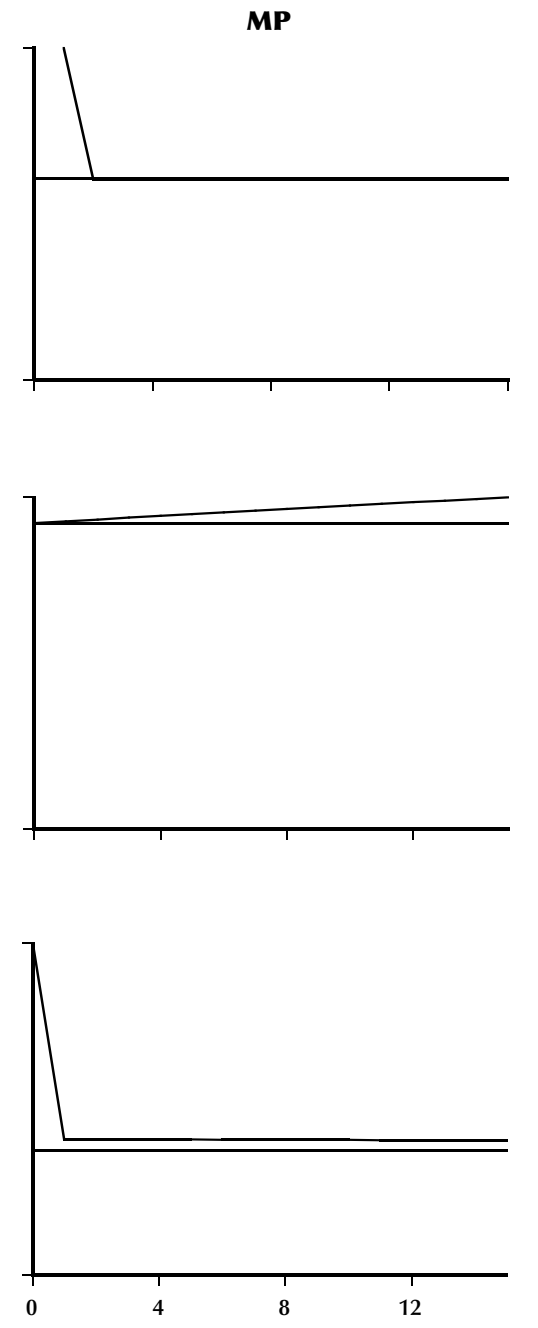
estimate the remaining parameters. Next we impose $\gamma_{\pi 1}=1.5$ and $\gamma_{x}=0.5$ in the Taylor rule and estimate the rest of the model. Both approaches produce sensible results, with monetary policy shocks having important effects on output. Inflation, however, appears to be entirely an aggregate supply phenomenon.

Imposing $1 / \sigma=2$ and not imposing Taylor's restriction on IS leads to the estimates

$$
\begin{aligned}
x_{t} & =-\underline{2.0} i_{t}+1.658\left(p_{t}-p_{t-1}\right)+0.063 \\
p_{t}-p_{t-1} & =0.077 x_{t-1}+\left(p_{t-1}-p_{t-2}\right) \\
i_{t} & =1.027\left(p_{t}-p_{t-1}\right)+1.535 x_{t}+0.030,
\end{aligned}
$$

where underlining indicates an imposed parameter value.

All the estimated parameters are reasonable. The IS elasticity with respect to inflation is positive, as one would expect if output depends on the real interest rate.

Most striking are the estimated policy parameters. The Fed raises the funds rate more than onefor-one with the inflation rate. It raises the funds rate about 150 basis points in response to a 1 percent increase in the output gap. A coefficient on inflation that exceeds 1 implies stabilizing policy, according to the standard interpretations of the policy rule (e.g., Taylor, 1999b, or Clarida, Gali, and Gertler, 1999). The system estimates in equation (11) are in sharp contrast to ordinary least-squares (OLS) estimates of the policy rule over this period:

$$
\text { OLS: } i_{t}=0.86\left(p_{t}-p_{t-1}\right)-0.14 x_{t}+0.03
$$

$$
\text { (0.07) (0.07) (0.003) }
$$

which would seem to suggest that policy was not stabilizing on average since 1959 . The substantive difference in estimates underscores the importance of estimating policy behavior and private behavior simultaneously. Inferences about policy behavior based on the system estimates in equation (10) are qualitatively different from those based on singleequation estimates in equation (12).

Figure 2 displays the system's responses to exogenous disturbances over four years. The third column shows that MP has important effects on output: a 100-basis-point exogenous contraction reduces output by 2 percent (as the calibrated value for $\sigma$ implies), though the effects die out immediately. Policy disturbances matter for output, accounting for over a third of its variability. Exogenous shifts in policy, however, have little impact on inflation.
Policy is strongly endogenous. Policy disturbances account for 20 percent of the variation in the funds rate over the first year and for 10 percent over longer horizons. Endogeneity of policy shows up in the responses of the funds rate to IS and AS disturbances. An IS shock that increases the output gap and gradually raises the price level, brings forth a higher funds rate. An outward shift in AS persistently raises the output gap, permanently lowers the price level, and induces the Fed to lower the funds rate. Only very gradually does the Fed return the rate to its initial level.

Monetary policy shocks are the dominant source of output variation (75 percent over the fouryear horizon), and AS disturbances are the sole source of price level movements (more than 98 percent over the horizon). AS shocks also account for three-quarters of funds rate variability at fouryear horizons.

Figure 3 displays the time paths of structural shocks implied by the estimated model. With the exception of the AS shock, the estimated disturbances exhibit strong patterns of serial correlation, which arise from the absence of dynamics in the behavioral equations. ${ }^{16}$ The time path of the monetary policy disturbances in the bottom panel of the figure resembles the "policy mistakes" that Taylor (1999a) reports in his historical analysis of policy rules. Taylor computes the gap between the actual funds rate and value of the rate implied by two policy rules. He concludes that when the gap was positive the funds rate was "too high" and when it was negative the funds rate was "too low." In Figure 3 , a positive value of $\varepsilon^{M P}$ is an exogenous tightening of policy and a negative value is an exogenous loosening. Unlike Taylor's work, the figure does not report that policy in the early 1960s was "too loose." It is consistent with Taylor's findings that in the second half of the 1960s and the 1970s policy was "loose," while in the early to mid-1980s policy was "tight." The figure is also generally consistent with Taylor in finding that through the 1990s "policy mistakes" were small.

We are unwilling, however, to draw the normative conclusions Taylor does. In the model, as Figure

\footnotetext{
${ }^{16}$ Clearly these errors are not i.i.d. as assumed in the estimation. Rather than estimate patterns of serial correlation for the shocks to render some residuals as white noise, we prefer to account for the data's persistence through behavioral relationships. Allowing serially correlated errors, as is common in the literature, would improve the fit, but would not contribute to the economic interpretation of the data.
} 


\section{Figure 2}

Dynamic Responses in Taylor's Model
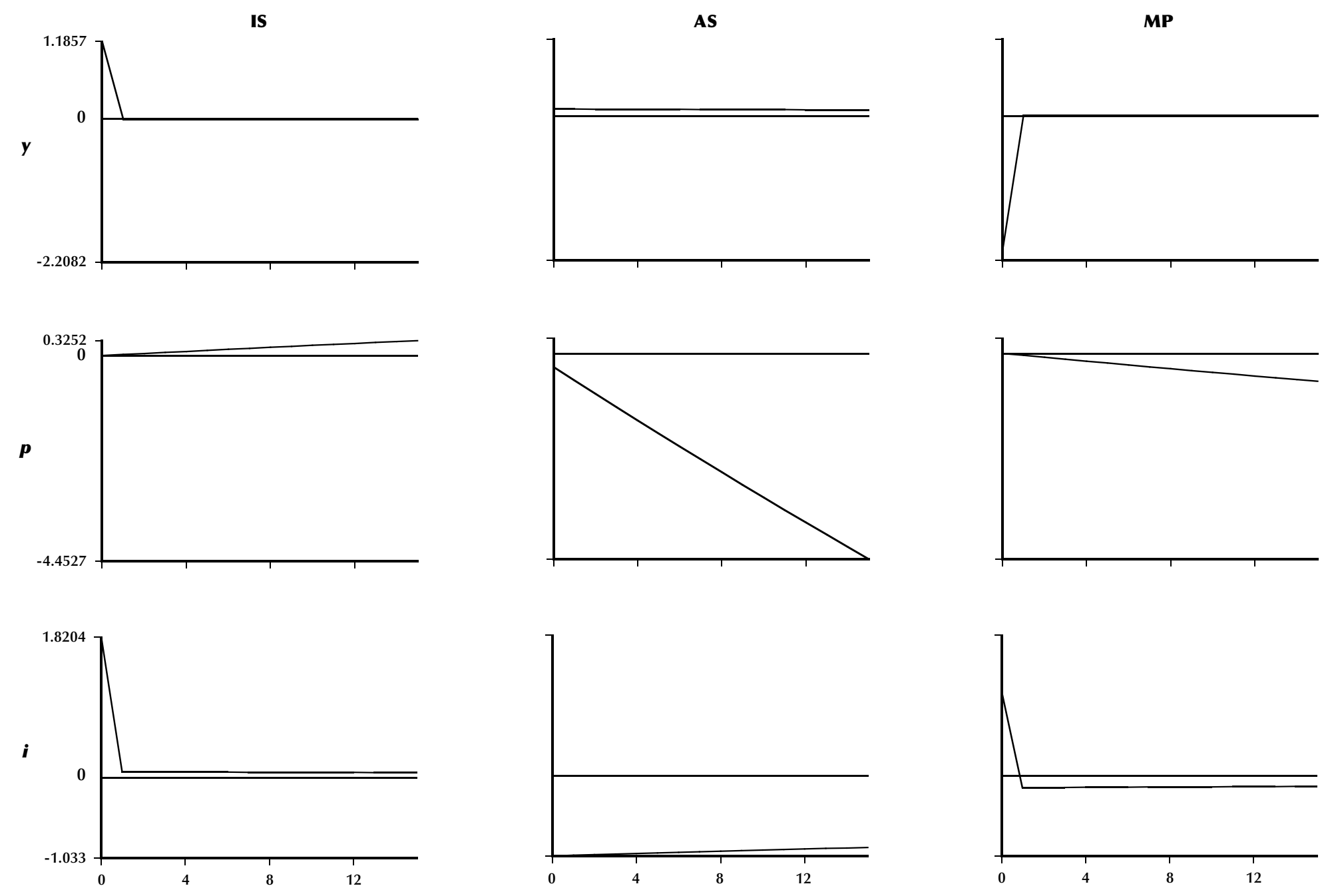


\section{Figure 3}

\section{Implied Shocks in Taylor's Model}
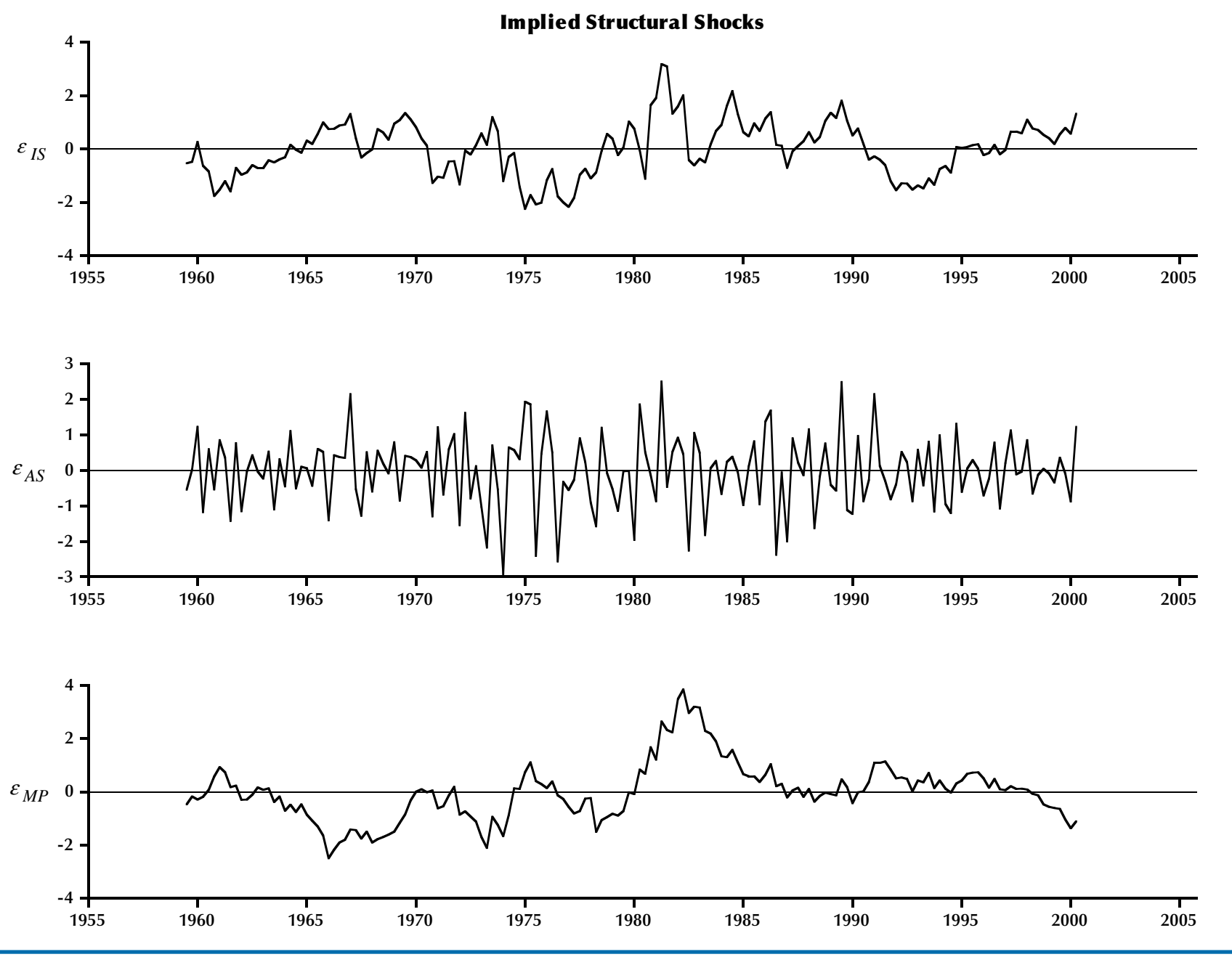

2 attests, exogenous shifts in policy have unrealistically large impacts on output and essentially no impacts on inflation. We prefer to link normative statements about policy to the impacts policy has on variables that affect private agents' welfare. If those estimated impacts are implausible, it seems premature to deduce how well policy has performed from the estimated pattern of residuals in the policy equation.

Not surprisingly, the data strongly reject equation (11), a model with severely pruned dynamics. Letting $\xi$ denote twice the difference of the log likelihoods of the unrestricted and restricted models, $\xi=2\left(\log \left(L_{U}\right)-\log \left(L_{R}\right)\right)$, we find $\xi=775.06$, which has a $p$-value of 0.00 . Critical values for the Schwarz and Akaike criteria are 122.4 and 48.
Imposing that policy be set according to the parameters Taylor (1993a, 1999a) employs $\left(\gamma_{\pi 1}=\right.$ $1.5, \gamma_{x 1}=0.5$ ) leads to the estimates

$$
\begin{aligned}
x_{t} & =-0.732 i_{t}+0.545\left(p_{t}-p_{t-1}\right)+0.024 \\
p_{t}-p_{t-1} & =0.077 x_{t-1}+\left(p_{t-1}-p_{t-2}\right) \\
i_{t} & =\underline{1.5}\left(p_{t}-p_{t-1}\right)+\underline{0.5} x_{t}+0.009
\end{aligned}
$$

where underlining indicates imposed parameter values. The qualitative impacts of the three disturbances are much like those depicted in Figure 2 and are not reported. Because the model's parameters are different, however, the quantitative implications differ somewhat. The estimated interest elasticity of IS is lower than in system (11), so the output 
effects of policy disturbances in this model are smaller, accounting for no more than 35 percent of output variability. AS shocks explain one-quarter of output forecast error variance and 80 percent of funds rate variability over four-year horizons.

It is difficult to distinguish the reduced-form expressions for IS and MP that emerge from the NK model without introducing additional restrictions. We showed that imposing an interest elasticity of IS of -2.0, which is in the ballpark for calibrated NK models, can solve the identification problem. Estimates of policy behavior from the 1959:Q1 to 2000:Q2 period are consistent with the interpretation that the Fed has, on average, been stabilizing: it raised the federal funds rate more than one-forone with inflation. This result comes from system estimates; OLS estimates of policy behavior produce a response to inflation that is substantially below 1.0. Although we solved the identification problem, the estimated models imply little role for monetary policy in influencing inflation.

\section{INFERENCES ABOUT STABILITY BASED ON POLICY PARAMETERS}

One piece of conventional wisdom to emerge from the NK work on MP is that policy is stabilizing when it raises the nominal interest rate more than one-for-one with the inflation rate. This increases the real interest rate, the argument goes, reduces aggregate demand, and counteracts the incipient inflation. In Taylor's policy rule, equation (4), this requires that $\gamma_{\pi 1}>1$. Several authors have drawn inferences about how policy impacts the economy based on estimates of $\gamma_{\pi 1}$ (e.g., Clarida, Gali, and Gertler, 1999, 2000; Rotemberg and Woodford, 1997, 1999; and Taylor, 1999a).

Stability is a characteristic of an equilibrium and, as such, is an implication of a model. Much of the recent work on simple rules may give the impression that one can deduce this model implication merely by estimating a policy rule. Implicitly, many authors are conditioning their assertions about the magnitude of a particular policy parameter on the structure and parameter values of an entire model.

Two different but related interpretations of U.S. monetary policy behavior before the VolckerGreenspan era stem from inferences about stability drawn from estimated policy rules. Taylor (1999b) argues in the following way that policy is "stabilizing" when $\gamma_{\pi 1}>1$. Modify the AS relationship in his model, equation (9), to be

$$
\text { AS: } \quad \pi_{t}=\lambda_{1} x_{t-1}+\delta \pi_{t-1}+\varepsilon_{t}^{A S} .
$$

Substituting MP into IS, and the resulting expression for $x$ into AS, yields a first-order difference equation describing the evolution of equilibrium inflation:

$$
\begin{aligned}
\pi_{t} & =\left(\frac{\lambda_{1}\left(1-\gamma_{\pi 1}\right)}{\sigma+\gamma_{x 1}}+\delta\right) \pi_{t-1} \\
& -\frac{\lambda_{1}}{\sigma+\gamma_{x 1}} \varepsilon_{t-1}^{M P}+\frac{\lambda_{1} \sigma}{\sigma+\gamma_{x 1}} \varepsilon_{t-1}^{I S}+\varepsilon_{t}^{A S} .
\end{aligned}
$$

Taylor imposes $\delta=1$. In that case, if $\lambda_{1}, \sigma, \gamma_{x 1}>0$, which are reasonable assumptions, then $\gamma_{\pi 1}>1$ is necessary and sufficient for equation (15) to be a stable difference equation. Suppose the economy is hit by an adverse AS shock that increases inflation. A sufficiently strong policy response to the initial increase in inflation would raise the real interest rate, reduce output, and stabilize inflation. In the absence of a strong policy response, output might rise and, through the AS relationship, raise inflation still more in the future. The process can be explosive.

A second interpretation of the implications of $\gamma_{\pi 1}<1$ comes from Rotemberg and Woodford (1997) and Clarida, Gali, and Gertler (2000). In a maximizing model with typical assumed values for private parameters, $\gamma_{\pi 1}<1$ implies that sunspot equilibria cannot be ruled out. Expectations of higher inflation that arise for unexplained reasons can be selffulfilling. Sunspot fluctuations may arise because economic agents rationally believe that the Fed will accommodate higher expected inflation by letting short-term real interest rates fall, stimulating aggregate demand, and raising inflation further. We do not pursue this interpretation in the present paper.

Both interpretations rely on estimates of $\gamma_{\pi 1}$ that are substantially below 1.0 in the United States before 1979.

We can see precisely the phenomenon that Taylor discusses when we reestimate the model in equation (10) over the sample 1959:Q1-1979:Q3. The estimates are

$$
\begin{gathered}
x_{t}=-2.621\left[i_{t}-\left(p_{t}-p_{t-1}\right)\right]+0.041 \\
p_{t}-p_{t-1}=0.105 x_{t-1}+\left(p_{t-1}-p_{t-2}\right) \\
i_{t}=0.671\left(p_{t}-p_{t-1}\right)+0.571 x_{t}+0.023 .
\end{gathered}
$$

The critical policy parameter, the response of the funds rate to inflation, is substantially less than 1 at 0.671 . According to conventional wisdom, policy 
was not stabilizing. Impulse response functions in Figure 4 bear out the conventional wisdom. Although the short-run patterns make economic sense, the responses to AS shocks are explosive, with output, the price level, and the funds rate shooting off to negative infinity. Explosiveness stems from the source Taylor highlights: the eigenvalue of the model's difference equation in inflation in equation (15) exceeds 1.0.17

It may be surprising that an important ingredient in generating instability is the restriction that $\delta=1$ in the AS specification in equation (14). We turn to the NK model laid out in Section II, but move away from the specific parameterization Taylor used. Instead, we consider an environment in which behavior in both the IS and the AS equations is dynamic.

To obtain restrictions motivated by the theoretical NK model, we calibrate and solve the model, deriving the theory's analogs to the $\left(A_{0}, A_{1}, A_{2}, C\right)$ matrices in the estimated model, equation (7). We then apply the pattern of linear restrictions implied by the theory to our empirical model. ${ }^{18}$ Let $X_{t}=$ $\left(x_{t}, p_{t}, i_{t}\right)^{\prime}$ and order the equations (IS, AS, MP). Let column $j$ of $A_{i}$ represent equation $j, j=$ IS, AS, MP. As an example, the pattern matrices for Taylor's (1999b) model, specified in equation (9) and estimated in equation (10), are

$$
A_{0}=\left[\begin{array}{ccc}
\times & 0 & \times \\
-\times_{1} & \times_{2} & \times_{3} \\
\times_{1} & 0 & \times
\end{array}\right], A_{1}=\left[\begin{array}{ccc}
0 & \times & 0 \\
-\times_{1} & 2 \times_{2} & \times_{3} \\
0 & 0 & 0
\end{array}\right], A_{2}=\left[\begin{array}{ccc}
0 & 0 & 0 \\
0 & -\times_{2} & 0 \\
0 & 0 & 0
\end{array}\right]
$$

where $\times$ denotes a freely estimated coefficient, 0 denotes a coefficient that is excluded, and $x_{i}$ denotes a coefficient estimated subject to a dynamic linear restriction within an equation. After estimation, setting the diagonal terms in $A_{0}$ to 1 normalizes the matrices. There are six freely estimated parameters in $A_{0}$, so the model is just identified. ${ }^{19}$

We now consider other versions of the NK model. IS and AS relationships are dynamic with both forward- and backward-looking behavior; policy follows the Taylor rule $i_{t}=2+1.5 \pi_{t}+0.5 x_{t}{ }^{20}$ The reduced form for this model implies the pattern matrices

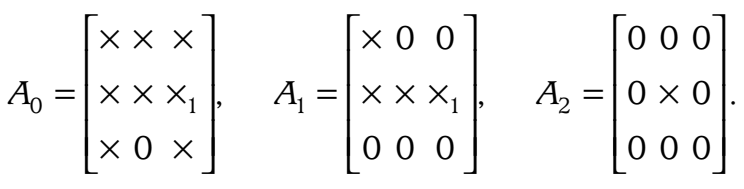

Now the model determines all three variables simultaneously. With eight free parameters in $A_{0}$, the model is not identified. We follow Taylor in forcing the effect of the output gap on inflation to occur with a one-period lag (making $A_{0}(1,2)=0$ and $\left.A_{1}(1,2)=\times\right)$, and we add the restriction that the nominal interest elasticity of IS is -2.0 : $\sigma=1 / 2\left(=A_{0}(3,1)\right)$. The estimated model for the period 1959:Q1-1979:Q3 is

(19)

$$
\begin{aligned}
& x_{t}=-\underline{2.0} i_{t}+1.126\left(p_{t}-p_{t-1}\right)+1.495 x_{t-1}+0.060 \\
& p_{t}=0.025 x_{t-1}+1.9615 p_{t-1}-0.9618 p_{t-2} \\
& i_{t}=0.690\left(p_{t}-p_{t-1}\right)+0.517 x_{t}+0.023 .
\end{aligned}
$$

Although we did not impose that the AS function can be written in terms of the inflation rate, the estimates are very close to $\pi_{t}=0.025 x_{t-1}+0.962 \pi_{t-1}$. As in system (16), we estimate that the policy response to inflation is well below one-for-one. This model, however, does not display the instability following AS shocks that appears in the previous model. Figure 5 displays the impulse response functions over a four-year horizon. All the responses look reasonable and converge after about 10 years. The absolute values of the largest eigenvalues of the estimated system are 0.996 and 0.997 . Evidently, $\gamma_{\pi 1}>1$ isn't necessary for stability.

Although the estimated response of policy to inflation is weak, policy behavior is strongly endogenous. Over forecast horizons of one to four years, over 20 percent of the fluctuations in the funds rate are due to IS shocks and 45 percent are due to AS shocks. Inflation is again estimated to be primarily an aggregate supply phenomenon, with 85 to 100 percent of price level variation due to AS shocks. Policy disturbances simply do not move the price level very much, though they are more important than IS shocks in accounting for output fluctuations

\footnotetext{
${ }^{17}$ The largest eigenvalue is estimated to be 1.036 .

${ }^{18}$ Because we do not impose the cross-equation restrictions that the theory implies, the empirical model may be underidentified even when the theoretical model is not.

${ }^{19}$ As equation (17) makes clear, there are additional restrictions among coefficients across the $A_{i}$ matrices. When we evaluate the order condition, we do not count these, and focus exclusively on restrictions on $A_{0}$. One could instead investigate achieving identification through the dynamic restrictions.

${ }^{20}$ We set $r=2, \sigma=1, \theta=0.2, \kappa=1, \lambda_{0}=0.3, \beta=0.99, \psi=0.2, \gamma_{0}=2$, $\gamma_{\pi 1}=1.5, \gamma_{x 1}=0.5$, and the remaining parameters to zero.
} 


\section{Figure 4}

An Unstable Equilibrium in Taylor's Model (1959:Q1-1979:Q3)
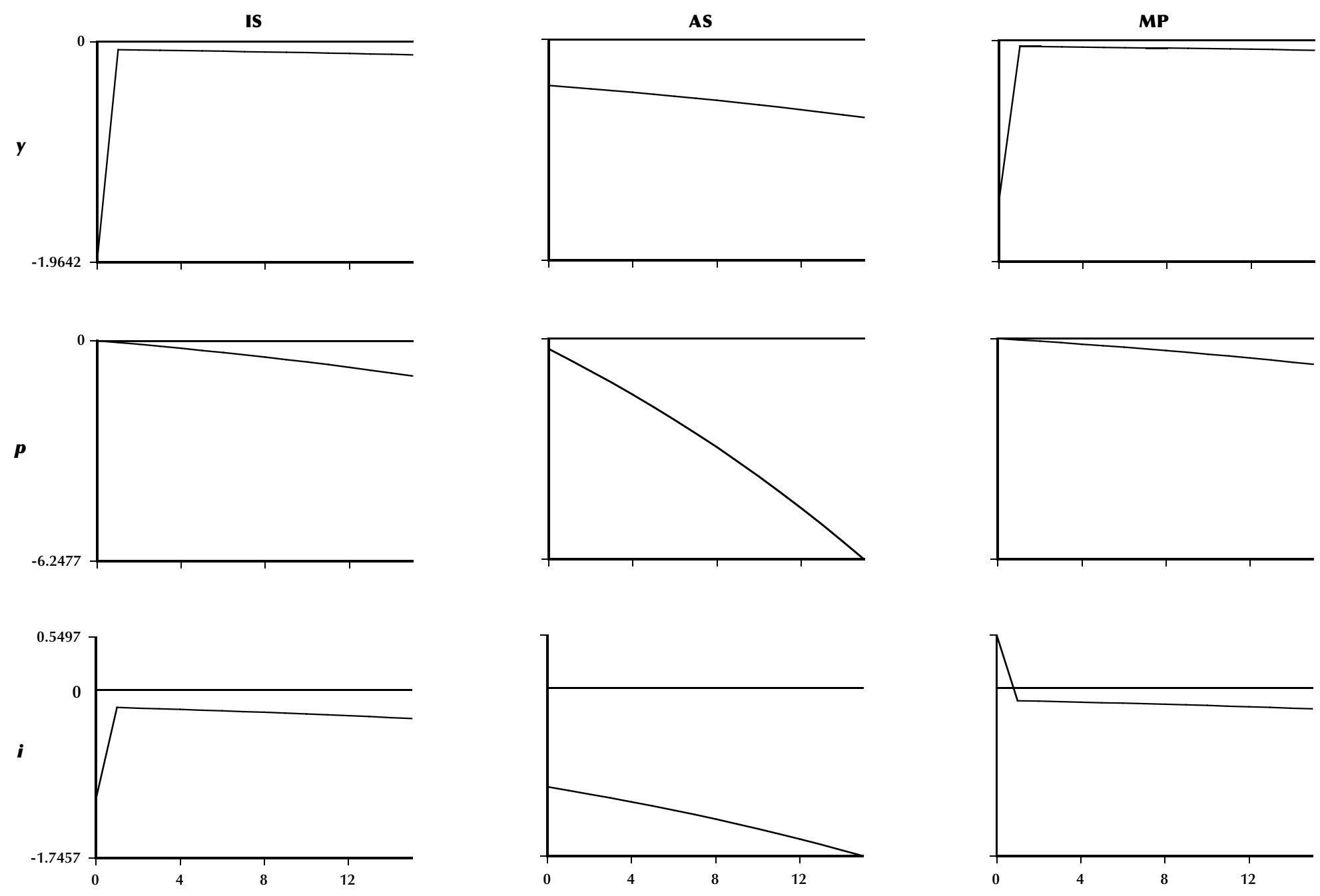


\section{Figure 5}

A Stable Equilibrium in Taylor's Model (1959:Q1-1979:Q3)
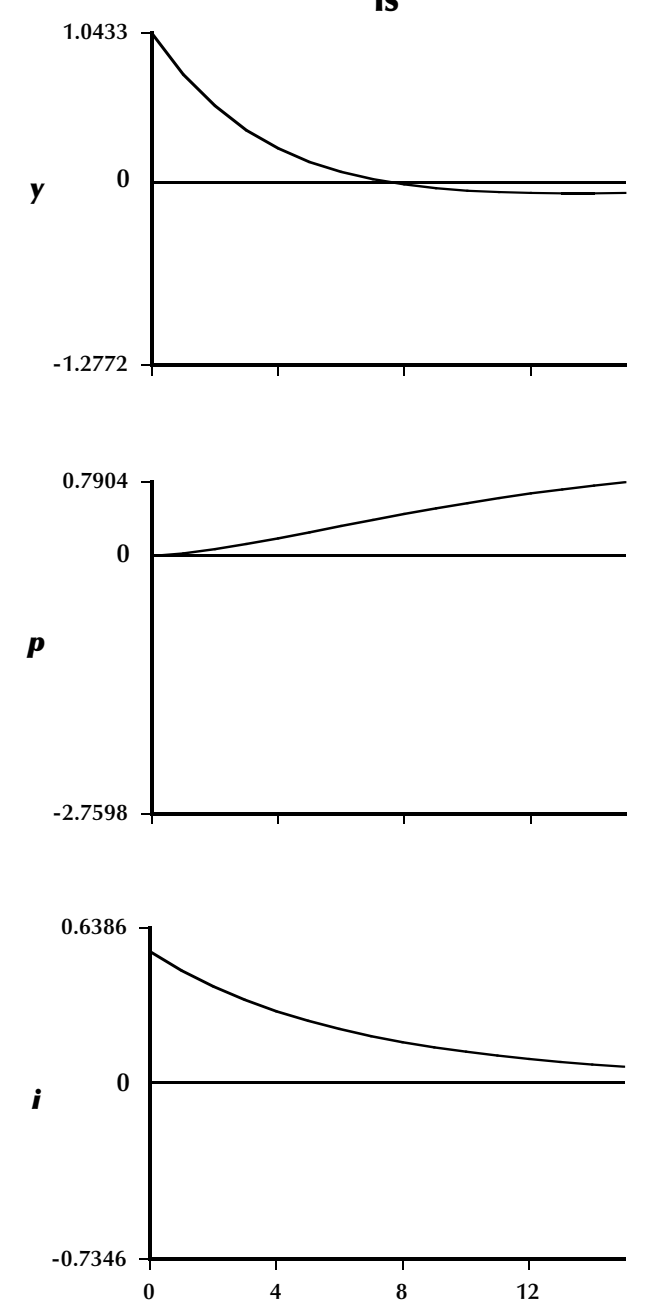

AS
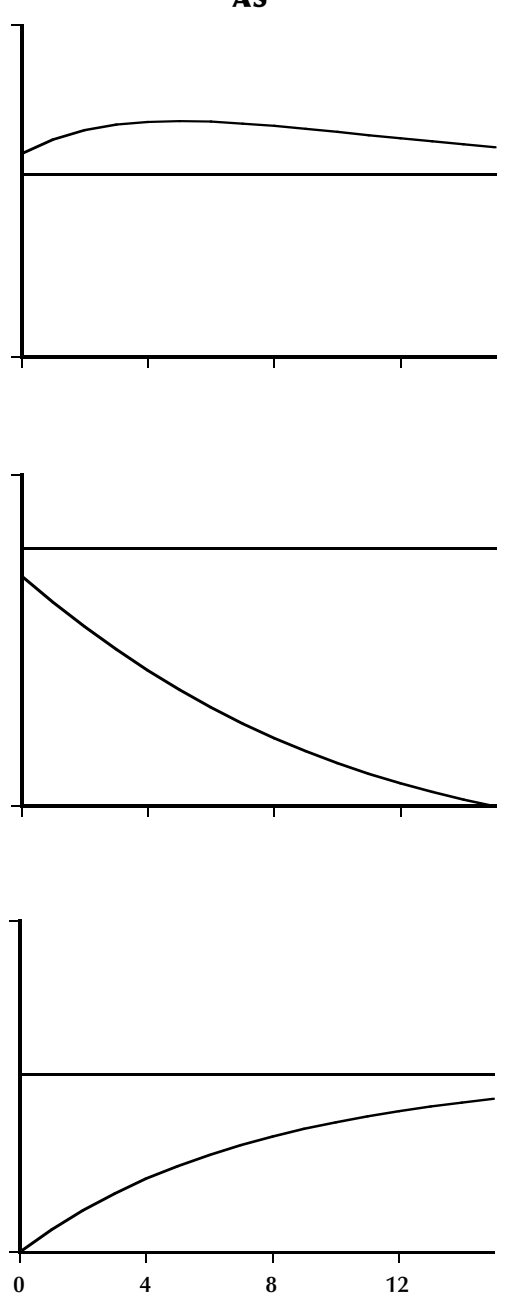

MP
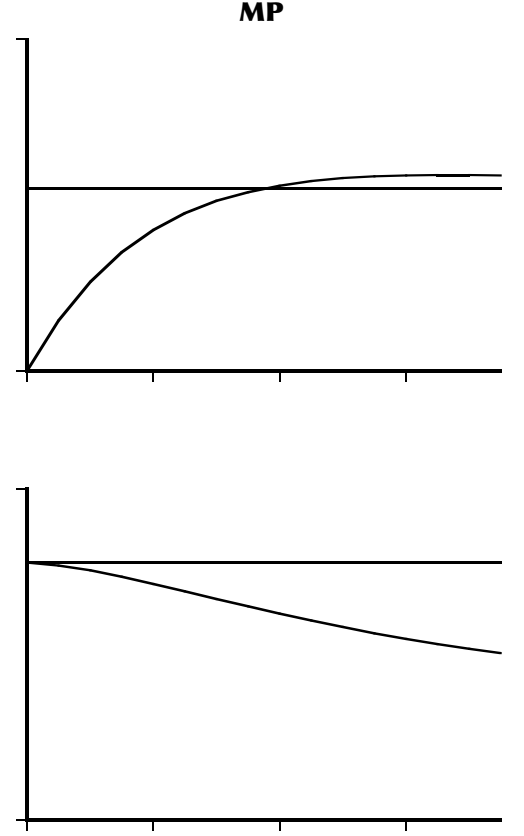

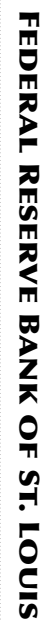


in the short run (60 percent versus 40 percent).

In spite of the widespread belief that the Fed raised the funds rate less than one-for-one with inflation in the period from 1959:Q1 to 1979:Q3, it is worthwhile estimating the same model with identification achieved by imposing the policy rule $i_{t}=\gamma_{0}+1.5 \pi_{t}+0.5 x_{t}$. With these two restrictions on $A_{0}$, we now freely estimate the interest elasticity of IS $\left(A_{0}(3,1)\right)$ and the contemporaneous effect of output on price setting behavior $\left(A_{0}(1,2)\right)$. The model determines $\left(x_{t}, i_{t}\right)$ simultaneously. The estimates are

$$
\begin{aligned}
x_{t} & =-0.555 i_{t}+0.069\left(p_{t}-p_{t-1}\right)+1.090 x_{t-1}+0.027 \\
p_{t} & =0.053 x_{t-1}+1.979 p_{t-1}-0.979 p_{t-2} \\
i_{t} & =\underline{1.5}\left(p_{t}-p_{t-1}\right)+\underline{0.5} x_{t}-0.11 .
\end{aligned}
$$

Once again the model is stable, with largest eigenvalues equal to 0.997 and 0.999 . Dynamic responses to exogenous disturbances look reasonable, as shown in Figure 6. The most notable quantitative difference between this model and the previous one, equation (19), is that now IS and MP disturbances are more important sources of inflation variation, accounting for 25 percent each over horizons of four years. AS shocks continue to be the dominant source of inflation in the short run, but over longer periods, aggregate demand is as important as aggregate supply.

We also estimated two versions of the NK model where AS behavior is forward looking only. IS continues to be forward and backward looking. Eliminating backward-looking price-setting behavior excludes current inflation from the IS equation. The resulting pattern matrices are

$$
A_{0}=\left[\begin{array}{ccc}
\times & \times & \times \\
0 & x_{1} & \times_{2} \\
\times & 0 & \times
\end{array}\right], \quad A_{1}=\left[\begin{array}{ccc}
\times & 0 & 0 \\
0 & x_{1} & x_{2} \\
0 & 0 & 0
\end{array}\right], \quad A_{2}=\left[\begin{array}{lll}
0 & 0 & 0 \\
0 & 0 & 0 \\
0 & 0 & 0
\end{array}\right] \text {. }
$$

One more restriction on $A_{0}$ is needed to identify the model. We considered (i) excluding $x_{t}$ from AS and (ii) imposing an interest elasticity of -2.0 on IS. In both cases the estimated models were stable in spite of the policy's less than one-for-one response of the funds rate to inflation.

Whether or not monetary policy is stabilizing depends on policy and private behavior. We found that over the pre-Volcker-Greenspan era (1959:Q11979:Q3), Fed behavior appears not to be stabilizing when we impose the Taylor (1999b) restrictions on aggregate supply. In contrast, when we impose AS restrictions implied by the dynamic NK model, policy over the period appears to be stabilizing. In both cases we estimate that the Fed adjusted the funds rate less than one-for-one with inflation.

\section{THE DISAPPEARANCE OF MONEY FROM MONETARY POLICY ANALYSES}

Money plays no role in NK models of monetary policy. To some observers this may seem odd. This section reviews and discusses the reasons for money's disappearance. The section then turns to some empirical implications of reintroducing money.

\section{Why Money Disappeared}

Money disappeared for both practical and theoretical reasons. Throughout the 1980s, the Federal Reserve paid fairly close attention to the growth of various monetary aggregates in setting its target for the federal funds rate. Target growth rates for aggregates were established and taken seriously by observers of monetary policy. A decade ago researchers at the Federal Reserve Board developed the "P-Star" model, which relied on stable long-run values of velocity and output growth, to use M2 growth to predict inflation (Hallman, Porter, and Small, 1991). Although doubts were raised at the time, any hope of exploiting M2 growth to forecast inflation evaporated when M2 velocity began to behave erratically in the early $1990 \mathrm{~s} .{ }^{21}$ Since then, as a practical move, the Fed has deemphasized growth rates of aggregates as indicators of inflation. In 2000, the FOMC formalized this deemphasis, as the minutes from the June $27-28,2000$, meeting indicate:

In contrast to its earlier practice, the Committee at this meeting did not establish ranges for growth of money and debt in 2000 and 2001. The legal requirement to set and announce such ranges recently had expired, and the members did not view the ranges as currently serving a useful role in the formulation of monetary policy. Owing to uncertainties about the behavior of the

\footnotetext{
${ }^{21}$ Christiano (1989) raised some doubts.
} 


$$
\begin{aligned}
& \overline{E V E} \\
& \bar{E} E \\
& E V E
\end{aligned}
$$


velocities of money and debt, these ranges had not provided reliable benchmarks for the conduct of monetary policy for some years. Nevertheless, the Committee believed that the behavior of these aggregates retained value for gauging economic and financial conditions and that such behavior should continue to be monitored. Moreover, Committee members emphasized that they would continue to consider periodically issues related to their long-run strategy for monetary policy, even if they were no longer setting ranges for the money and debt aggregates.

Theoretical developments in the past decade reinforce the Fed's pragmatic response to unstable M2 velocity. Several authors showed that a nominal anchor need not come from control of a monetary aggregate: a policy rule that sets the nominal interest rate can uniquely determine the price level even in a rational expectations model. 22 This contradicted Sargent and Wallace's (1975) famous result that interest rate rules cannot determine the price level. ${ }^{23}$ These developments initiated a literature about interest rate rules that continues to flourish. 24

Several considerations arise from the absence of money in the analytical framework. First, even if the Fed ignores money when it sets the funds rate, this does not imply that money plays no role in the transmission of monetary policy or in individuals' and firms' consumption, investment, employment, and pricing decisions. In terms of the NK model, absence of money from the policy rule does not justify its absence from the IS and AS relationships. Interest rates need not be the only channel through which monetary policy affects economic activity.

Second, the fact that the Fed can ignore money without losing a nominal anchor does not imply the Fed does ignore it. The FOMC minutes leave open the possibility that the Fed may again choose to pay more attention to monetary aggregates. For example, it is hard to imagine that if M2 growth were to exceed 20 percent for four consecutive quarters that there would be no tendency for the FOMC to adjust its funds rate target in response.

Third, even if the Fed now ignores money, it certainly has not always ignored it. Historical interpretations of policy behavior that ignore money run the risk of seriously misinterpreting past policy actions.
Finally, if money plays any role at all in the FOMC's settings for the funds rate, then money is likely to enter private sector expectations of future funds rates. Money, therefore, will enter dynamic IS or AS relationships through the expectations terms, once expectations are solved out.

\section{Adding Money}

We add to the NK model a function that makes the demand for real money balances (MD) depend on the current nominal interest rate and current income. To focus on the marginal contribution of adding money to a model with simple policy rules, we adopt an agnostic view of the dynamics associated with IS, AS, and MD behavior. We posit the money demand function

$$
\mathrm{MD}: \quad M_{t}-p_{t}=\alpha_{0}+\alpha_{i} i_{t}+\alpha_{y} y_{t}+\text { lags }+\varepsilon_{t}^{M D},
$$

where $M$ is a broad monetary aggregate, $y$ is output (or income), and $\varepsilon^{M D}$ is an exogenous disturbance to the demand for money. We exclude potential output entirely from MD. Money enters the econometric models in logged form.

Money is taken to be M2. Clearly, the federal funds rate is not the opportunity cost of M2. Based on the large models estimated in Leeper, Sims, and Zha (1996), modeling the details of the links between the markets for reserves and broad money complicate but do not substantively change the analysis. In addition, Gordon and Leeper (1994) found that correctly accounting for the own rate of return on M2 in computing the opportunity cost does not appreciably alter the conclusions that concern us here.

As discussed in Section II, there is the potential for confounding behavior described by IS with that described by either MD or MP. For the present purposes, we seek to minimize those identification problems by treating $\left(y_{t}, p_{t}\right)$ as being determined in an "inertial" sector of the economy. This assumption

\footnotetext{
22 Authors include McCallum (1981, 1983) and Leeper (1991). Related work falls under the rubric of the "fiscal theory of the price level" advocated by Sims (1994) and Woodford (1998).

${ }^{23}$ Sargent (1979) states the result as follows: "There is no interest rate rule that is associated with a determinate price level" (p. 362). Predecessors to Sargent and Wallace that do not impose rational expectations include Patinkin (1949) and Gurley and Shaw (1960).

${ }^{24}$ Analyses of the price level, inflation, and monetary policy without money are creeping into principles textbooks (see Romer, 2000 and Stiglitz and Walsh, 2000).
} 
treats output and inflation as predetermined for monetary variables: disturbances to MD and MP behavior affect $y$ and $p$ with a one-period lag. By lumping output and price determination into a single sector, we can no longer claim to have identified behavioral IS and AS equations; instead, we now have " $x$ " and " $p$ " equations.

The empirical work in this section contrasts two assumptions about policy behavior: the conventional Taylor rule, as given by equation (4), and an even simpler rule in which the Fed's choice for the funds rate depends only on current money growth 25 :

(23) MP(M rule): $i_{t}=\gamma_{0}+\gamma_{m 1}\left[\left(M_{t}-M_{t-1}\right)-\bar{\mu}\right]+\varepsilon_{t}^{M P}$.

We have chosen to normalize this rule on the nominal interest rate, but it is equally consistent to imagine this as a rule that determines the supply of money, where that supply choice is sensitive to the nominal interest rate.

We order the equations " $x$," " $p$," MD, and MP and the variables $x, p, M$, and $i$. Common to both assumptions about policy behavior are the pattern matrices

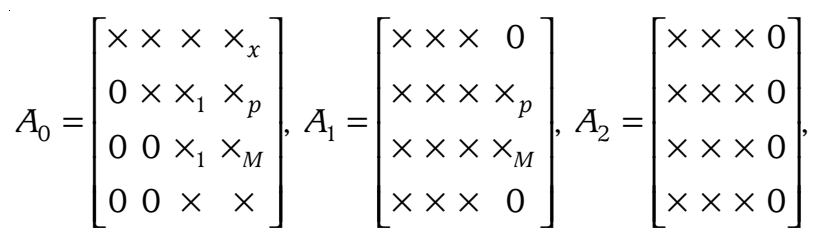

where either $\times_{x}$ and $\times_{p}$ are non-zero with $\times_{M}=0$ (conventional Taylor rule) or $x_{M}$ is non-zero with $\times_{x}=\times_{p}=0$ (M rule). Coefficients denoted $\times_{1}$ reflect the homogeneity restriction making money demand the demand for real balances. The specification removes any dynamics from policy behavior.

We estimate the models from 1959:Q1 to 2000:Q2. For the model with the Taylor rule, estimates of the coefficients in $A_{0}$ imply

$$
\begin{aligned}
\left(M_{t}-p_{t}\right)^{d} & =-0.242 i_{t}+0.204 y_{t} \\
i_{t} & =0.873\left(p_{t}-p_{t-1}\right)-0.045 x_{t},
\end{aligned}
$$

where we suppress the lagged coefficients in money demand, all constants, and the coefficient on the output gap in the price equation. ${ }^{26}$ It is clear that when the demand for money is appended to this model with a Taylor rule for policy, the variables can be solved recursively: the first equation yields $x_{t}$, which from the second equation implies $p_{t}$; together these yield $i_{t}$ from the policy rule in equation (25), and $M_{t}$ comes from the money demand equation in equation (25), given the value for exogenous potential output, $y_{t}^{p}$. Because $M$ and $i$ are not determined simultaneously, estimates of money demand have no effect on estimates of policy behavior.

The estimated parameters in equation (25) seem reasonable. The short-run semi-elasticity of money demand is negative, and the short-run income elasticity is positive. In contrast to what we found when estimating a model with severely restricted dynamics (see equation (11)), policy appears to adjust the funds rate less than one-forone with inflation. This difference underscores the importance of all the model's identifying assumptions when drawing inferences about policy behavior from estimated policy rules. Model (11) determines $x$ and $i$ simultaneously through IS behavior; model (25) determines them recursively due to inertial behavior. In spite of the estimated policy behavior, the model is stable.

Figure 7 shows the Taylor rule applied to response functions over a four-year horizon. Responses to MP shocks are depicted in the fourth column: a policy contraction raises the funds rate substantially and reduces the money stock, generating a liquidity effect. Output has a strange positive blip in the quarter after the shock, but then declines, following a hump-shaped path. There is no effect on the price level. Policy disturbances explain, at most, 13 percent of output, 41 percent of M2, and, in the initial period, over 80 percent of the funds rate. After four years, only 40 percent of funds rate variability is due to MP disturbances.

The endogeneity of policy appears in the first three panels of the bottom row of the figure. An " $x$ " shock, which reduces output and the price level, produces a modest response from policy, while a " $p$ " shock, which moves output and inflation in opposite directions, engenders a stronger offsetting reaction. Over 40 percent of funds rate fluctuations at four-year horizons arise from reactions to " $p$ " shocks.

Policy also responds to money demand disturbances. An MD shock lowers M2 on impact. This is

\footnotetext{
25 In estimation, we annualize the growth rate of money, so $4\left(M_{t}-\mathrm{M}_{t-1}\right)$ appears in (23).

26 All current and lagged coefficients in the output and price equations are identical between the two models with two different policy rules.
} 


\section{Figure 7}

Model with Money and a Taylor Rule (1959:Q1-2000:Q2)
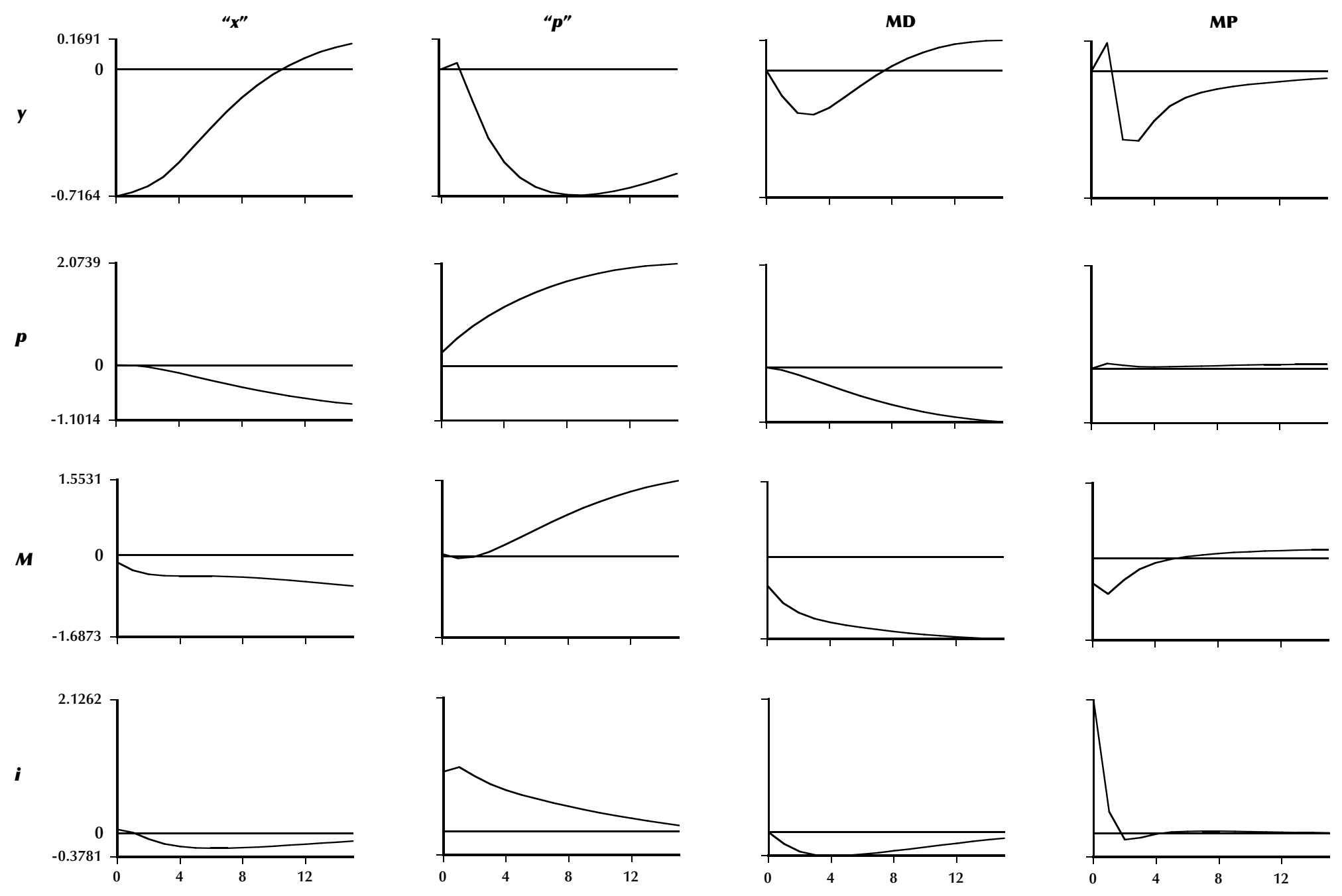


\section{Figure 8}

Model with Money and a Money Rule (1959:Q1-2000:Q2)
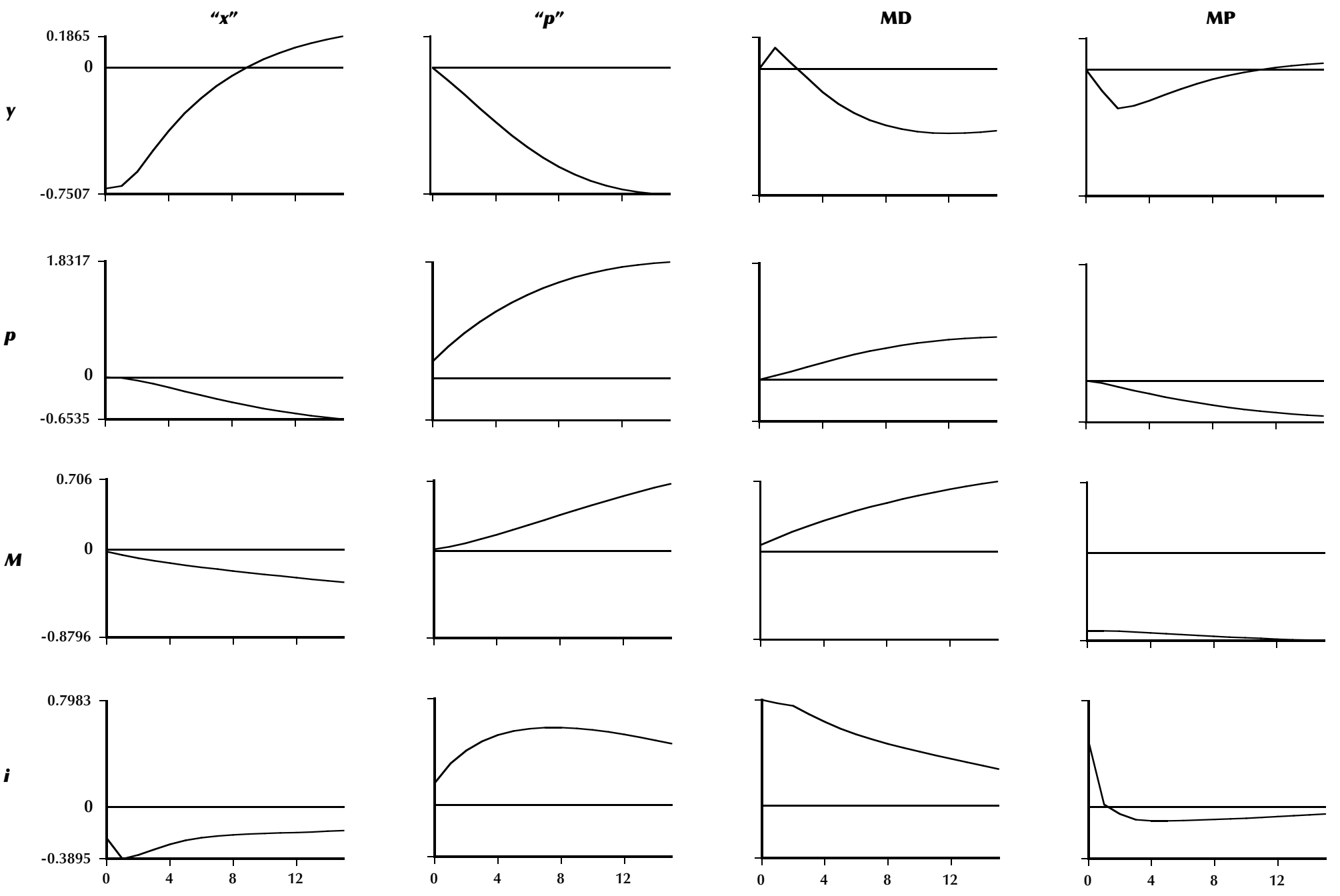
followed by falling prices and initially lower output; after about two years, output rises above its initial level. ${ }^{27}$ Policy raises the funds rate smoothly, gradually returning it to its pre-shock level. The Taylor rule prevents the funds rate from jumping when MD shocks strike.

Estimates of the model with the alternative $M$ rule in equation (23) yield 28 :

$$
\begin{aligned}
\left(M_{t}-p_{t}\right)^{d} & =-1.571 i_{t}+0.554 y_{t} \\
i_{t} & =2.913\left(M_{t}-M_{t-1}\right) .
\end{aligned}
$$

The large estimated coefficient on money growth, by conventional wisdom, implies that policy was stabilizing. ${ }^{29}$ The model is no longer recursive, as the equations in equation (26) simultaneously determine $M$ and $i$. Note that the negative correlation between money and interest rates, which equation (25) attributes entirely to the interest elasticity of money demand, now gets split into a stronger negative demand elasticity and a positive supply elasticity.

Dynamic responses to the shocks in the "inertial" sector, shown in Figure 8, are similar to those in the model with a Taylor rule. From the standpoint of endogenous reactions to the disturbances that have occupied much of the attention of NK authors, the two policy rules are nearly indistinguishable. Some differences show up in the effects of exogenous shifts in policy: with an M rule a contraction generates a hump-shaped decrease in output and a smooth decline in the price level.

Three differences between the models are worth noting. First, comparing Figure 7 and Figure 8, a monetary contraction under a Taylor rule only temporarily changes the level of the money stock, while under an $\mathrm{M}$ rule it does so permanently. This implies that under a Taylor rule, the open market operation that initially raises the funds rate must be reversed to bring the money stock back to its original level. Second, the money stock appears to be more endogenous under an M rule: at most, 20 percent of the variation in $M$ is attributed to exogenous MD shocks. With a Taylor rule, over 60 percent of $M$ fluctuations are due to MD, providing a substantial role to exogenous factors in determining the money supply.

Finally, we formally test the overidentifying restrictions in the two models. The model with a Taylor rule imposes one less restriction than does the model with an M rule. We obtain:

$\begin{array}{ll}\text { Taylor rule } & \text { M rule } \\ \xi=418.3 & \xi=207.4 \\ \mathrm{SC}=112.2 & \mathrm{SC}=117.3 \\ \mathrm{AC}=44 & \mathrm{AC}=46 \\ p=0.00 & p=0.00\end{array}$

where SC is the Schwarz criterion and AC is the Akaike criterion. By any criterion the data reject both models. The test statistic in the M rule model is substantially less than in the Taylor rule model. These results suggest that a rule that makes the nominal interest rate respond to money growthand nothing else-certainly fits no worse than a Taylor rule.

Estimates of identical models under two qualitatively different policy rules yield fairly similar results when judged by system properties like impulse response functions and stability. Based solely on estimated policy rules, however, the two models look very different.

\section{The Recent Period}

Much current research on Federal Reserve behavior draws sharp distinctions between the pre-1979 and the post-1979 periods. Rotemberg and Woodford (1997) focus on the 1980-95 period, Fuhrer and Estrella (1999) consider breaks in policy occurring in 1979:Q3, 1982:Q3, and 1987:Q2, while Taylor (1999a) estimates his rule from 1987:Q1 to 1997:Q3. We reestimate the two models in equations (25) and (26) over the period 1982:Q1-2000:Q2. The NK literature has concluded that during this period the Fed stabilized the economy by adjusting the funds rate strongly in response to inflation; it is also a period in which many authors believe no harm is done by ignoring money.

Estimates from the model with a Taylor rule are

$$
\begin{aligned}
\left(M_{t}-p_{t}\right)^{d} & =-0.182 i_{t}+0.303 y_{t} \\
i_{t} & =0.311\left(p_{t}-p_{t-1}\right)+0.269 x_{t} .
\end{aligned}
$$

System estimates do not recover a policy response to inflation that is even close to exceeding 1.0. In

\footnotetext{
27 Textbook analyses typically have positive money-demand shocks lowering the price level. In simulations of the NK model, however, the pattern depicted in Figure 7 is common

${ }^{28}$ Separate coefficients on $M_{t}$ and $M_{t-1}$ are estimated to be 2.913 and -2.902 , so imposing equal and opposite coefficients does not move the estimates far from the peak of the likelihood function.

29 In the NK model, this coefficient also eliminates indeterminacy of equilibria.
} 
contrast, OLS estimates of the policy rule yield

$$
\text { OLS: } \quad i_{t}=1.03\left(p_{t}-p_{t-1}\right)-0.13 x_{t}+0.035
$$

which is consistent with conclusions of earlier authors that policy was stabilizing. Impulse response functions for the model estimate a small anomalous price response following an exogenous monetary policy contraction (not reported).

Estimates of the model with an $\mathrm{M}$ rule over the 1982:Q1-2000:Q2 period offer a different interpretation of policy behavior:

$$
\begin{aligned}
\left(M_{t}-p_{t}\right)^{d} & =-4.503 i_{t}+1.442 y_{t} \\
i_{t} & =1.272\left(M_{t}-M_{t-1}\right) .
\end{aligned}
$$

With the response of the funds rate to money growth exceeding 1.0 , policy appears to be stabilizing. OLS estimates of the policy rule tell a different tale:

$$
i_{t}=0.344\left(M_{t}-M_{t-1}\right)+0.049 \text {. }
$$

Responses to MP shocks in this model are not reported because they look very similar to those in Figure 8.

This section has presented evidence that the exclusion of money from NK empirical analyses is not innocuous. Substantive conclusions about the role of monetary policy and the behavior of the Federal Reserve can change when money is reintroduced in a way that generates interactions between MD and MP behavior. We also demonstrated that in practice it is difficult to distinguish a monetary policy that adjusts the nominal interest rate in response to inflation and output from a policy that adjusts the rate in response to the growth rate of the money supply. This raises some doubts that either specification of monetary policy-equation (27) or equation (29) -identifies policy decision rules. Instead, they may merely be alternative characterizations of equilibrium policy behavior.

In our results, the model with an $\mathrm{M}$ rule looks more reasonable than the model in which money is irrelevant to policy choice. These results seem to be at odds with Ireland (2000) and McCallum (2000). They show that money plays a quantitatively unimportant role in the class of general equilibrium models that includes NK models. The inconsistency between their quantitative-theoretic results and our empirical findings deserves further study.

\section{STABILITY IN AN IDENTIFIED VAR FRAMEWORK}

Section II estimated tightly parameterized behavioral relationships with simple policy rules. Section IV loosened the restrictions on dynamics in equations, describing private behavior while it maintained simple static policy rules. To complete the progression, this section allows also for freely estimated dynamics in policy behavior, leading to specifications in line with the approach taken in the identified VAR literature.

We show that when dynamics are left unrestricted, the models exhibit remarkable stability across subperiods. With the loss of parsimony comes increased sampling error and less precisely estimated parameters. To reduce sampling error we adopt the Bayesian methods developed by Sims and Zha (1998) and employed by Leeper, Sims, and Zha (1996) and Leeper and Zha (2001).

This section reports estimates from two weakly identified VARs. First we revisit the three-variable system consisting of output, the price level, and the federal funds rate. Although the system is fairly stable over time, it exhibits the price puzzle that has received attention in VAR work: an exogenous easing of policy lowers the funds rate, raises output, and lowers inflation. 30 The second model adds money to the system with two important effects: the price puzzle disappears and the responses to exogenous shifts in policy become more stable.

In choosing subperiods we face the usual problem that some "interesting" episodes may be too short to be informative. With brief time series, sampling error alone can dominate the estimates and produce misleading inferences. We check stability by estimating the system over three subperiods that coincide with ones frequently studied in work on Fed behavior: 1959:Q1-2000:Q2, 1959:Q1 1979:Q3, and 1959:Q1-2000:Q2 with 1979:Q41982:Q4 excluded. The models are estimated with four unrestricted lags and a constant term in each equation. ${ }^{31}$ We found that adding potential GDP contributes little to the interpretation of results in this section, so we have dispensed with that variable.

\footnotetext{
${ }^{30}$ Sims (1992) and Eichenbaum (1992) discuss the price puzzle.

31 In Sims and Zha's (1998) notation, the tightness of the prior is set as $\lambda_{0}=0.5, \lambda_{1}=0.4, \lambda_{2}=\lambda_{3}=1.0, \lambda_{4}=0.2, \mu_{5}=1.0$, and $\mu_{6}=5$.
} 


\section{Three-Variable Model}

As in Section IV, we treat output and inflation as determined in an inertial sector of the economy. This implies policy disturbances affect $y$ and $p$ with a one-period lag. We also take seriously the argument that an operational policy rule must make policy choice depend on observables. In the threevariable economy, where $y$ and $p$ are not observed contemporaneously, an operational rule sets the funds rate as a function of lagged values of all three series.

Because the VAR coefficients in this model are not interpretable, we move directly to the impulse response functions displayed in Figure 9. In each panel we report the three point estimates that correspond to the three subperiods and show a shaded region, which is a 68 percent error band associated with the model estimated from 1959:Q1 to 1979:Q3.32 When, for the three subperiods, the responses to a shock fall within the error bands, the model makes stable predictions of the effects of that shock. For many policy purposes, this is sufficient evidence of stability.

Most responses over a four-year horizon fall within the error bands. Notable exceptions are the response of output and prices to a policy disturbance: the impacts of policy appear to weaken as more recent data are included in the sample. Another difference is that over the full sample, the funds rate responds more strongly to a " $p$ " shock. This pattern is consistent with the view that, in the Volcker-Greenspan era, the Federal Reserve has placed increased emphasis on stabilizing inflation. Because in the model, both " $p$ " and " $y$ " shocks move output and prices in the same direction, they are both consistent with disturbances that shift aggregate demand. No shock in the model looks like aggregate supply.

Exogenous monetary expansions have strong and persistent effects on output. Even after four years, output remains well above its pre-shock level. The perverse response of the price level, though less pronounced in recent data, is consistent across subperiods. The stronger price puzzle exhibited in data up to 1979 conforms to Hanson's (2000a) findings in a different system of variables.

Figure 9 exhibits anomalies and enough instability that we are not comfortable with the identification of policy in the model. To address our concerns, we turn to a model with money.

\section{Four-Variable Model}

To identify policy behavior in the four-variable model with money, it is crucial to separate money demand from policy. We estimate the pattern matrix on contemporaneous variables

$$
A_{0}=\left[\begin{array}{cccc}
x & \times & \times & 0 \\
0 & \times & \times & 0 \\
0 & 0 & \times & \times \\
0 & 0 & \times & \times
\end{array}\right],
$$

where the equations appear in columns in the order " $y$," " $p$," MD, MP, and variables appear in rows ordered $y, p, M, i$. We impose no additional restrictions on this matrix and no restrictions on lagged variables. Over the three sample periods, the estimates of $A_{0}$ are

$$
\begin{gathered}
A_{0}^{59-79}=\left[\begin{array}{cccc}
1 & 0.02 & -0.18 & 0 \\
0 & 1 & -1.17 & 0 \\
0 & 0 & 1 & -8.71 \\
0 & 0 & 1.49 & 1
\end{array}\right], A_{0}^{59-00}=\left[\begin{array}{cccc}
1 & 0.02 & -0.43 & 0 \\
0 & 1 & -0.59 & 0 \\
0 & 0 & 1 & -9.93 \\
0 & 0 & 1.44 & 1
\end{array}\right], \\
A_{0}^{\text {no } 79-82}=\left[\begin{array}{cccc}
1 & 0.03 & -0.43 & 0 \\
0 & 1 & -1.89 & 0 \\
0 & 0 & 1 & 13.29 \\
0 & 0 & 3.47 & 1
\end{array}\right] .
\end{gathered}
$$

In all periods, money demand is estimated to have a negative interest elasticity and positive price and income elasticities. Over the entire sample and over the period up to 1979, the Fed raised the funds rate in response to higher money growth. When the 1979-82 period is excluded, the policy response to current money growth changes from positive to negative. It may be tempting to infer that policy behavior changed in important ways. This parameter is one of many that describes policy behavior in the VAR. The implications of changes in that parameter must be gleaned from the entire model.

Figure 10 illustrates the pitfalls of inferring policy behavior from a single parameter in the policy rule. Dynamic responses to policy disturbances are remarkably stable. Point estimates from the three subperiods lie within the 68 percent error bands derived from the 1959-79 period. There is

\footnotetext{
32 The error bands are computed from 50,000 draws using procedures developed by Sims and Zha (1999) and Waggoner and Zha (2000).
} 


\section{Figure 9}

\section{Three-Variable Identified VAR Over Various Sub-Periods}

-1959:Q1-2000:Q2; -- 1959:Q1-1979:Q3; --- 1959:Q1-2000:Q2 excluding 1979:Q4-1982:Q4
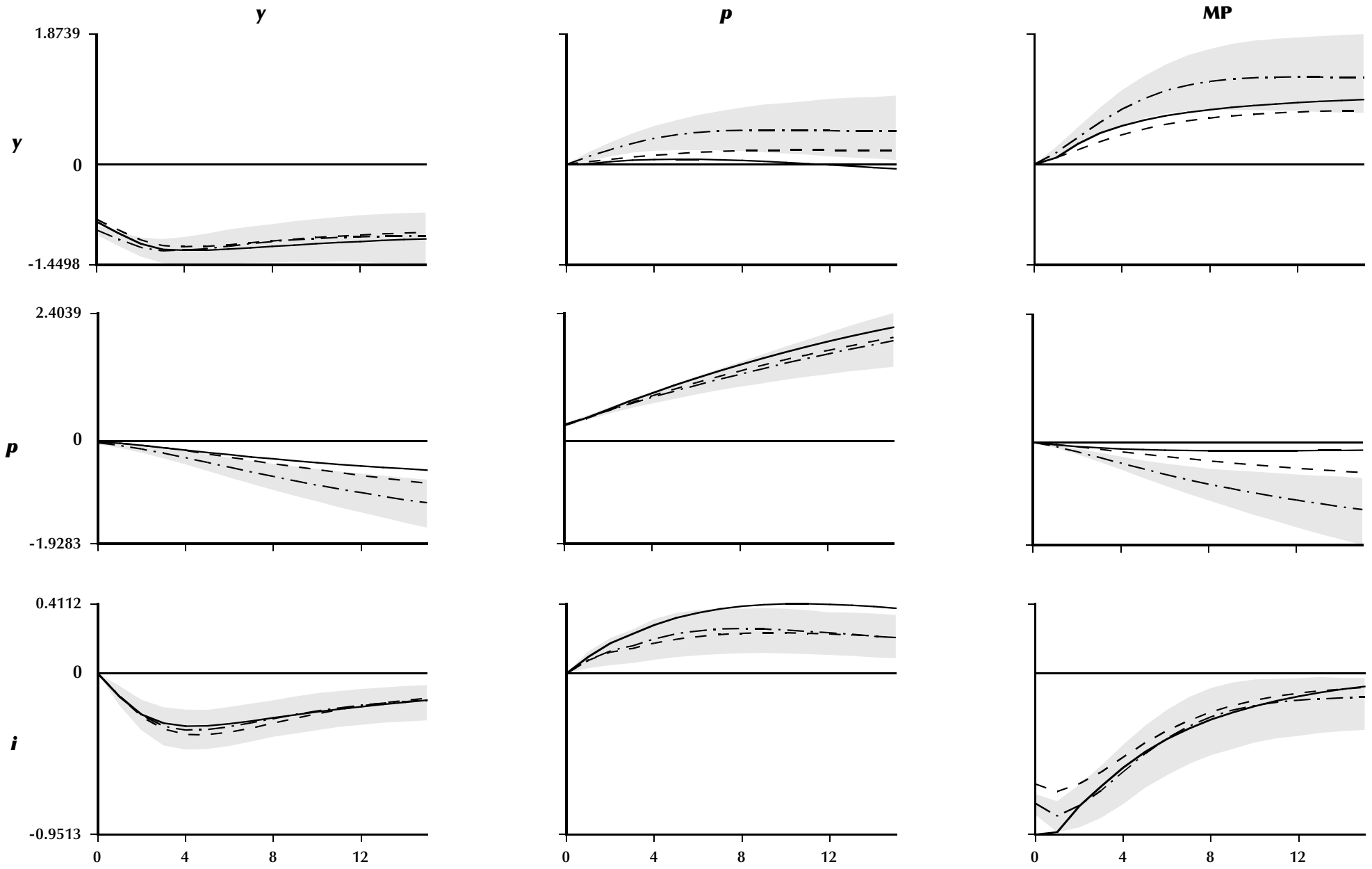

NOTE: The shaded region is a 68 percent error band associated with the model estimated from 1959:Q1 to 1979:Q3. 


\section{Four-Variable Identified VAR Over Various Sub-Periods}

-1959:Q1-2000:Q2; - - 1959:Q1-1979:Q3; --- 1959:Q1-2000:Q2 excluding 1979:Q4-1982:Q4
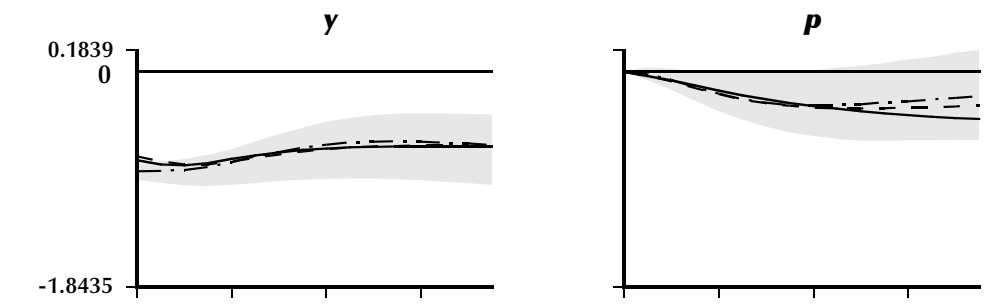

MD
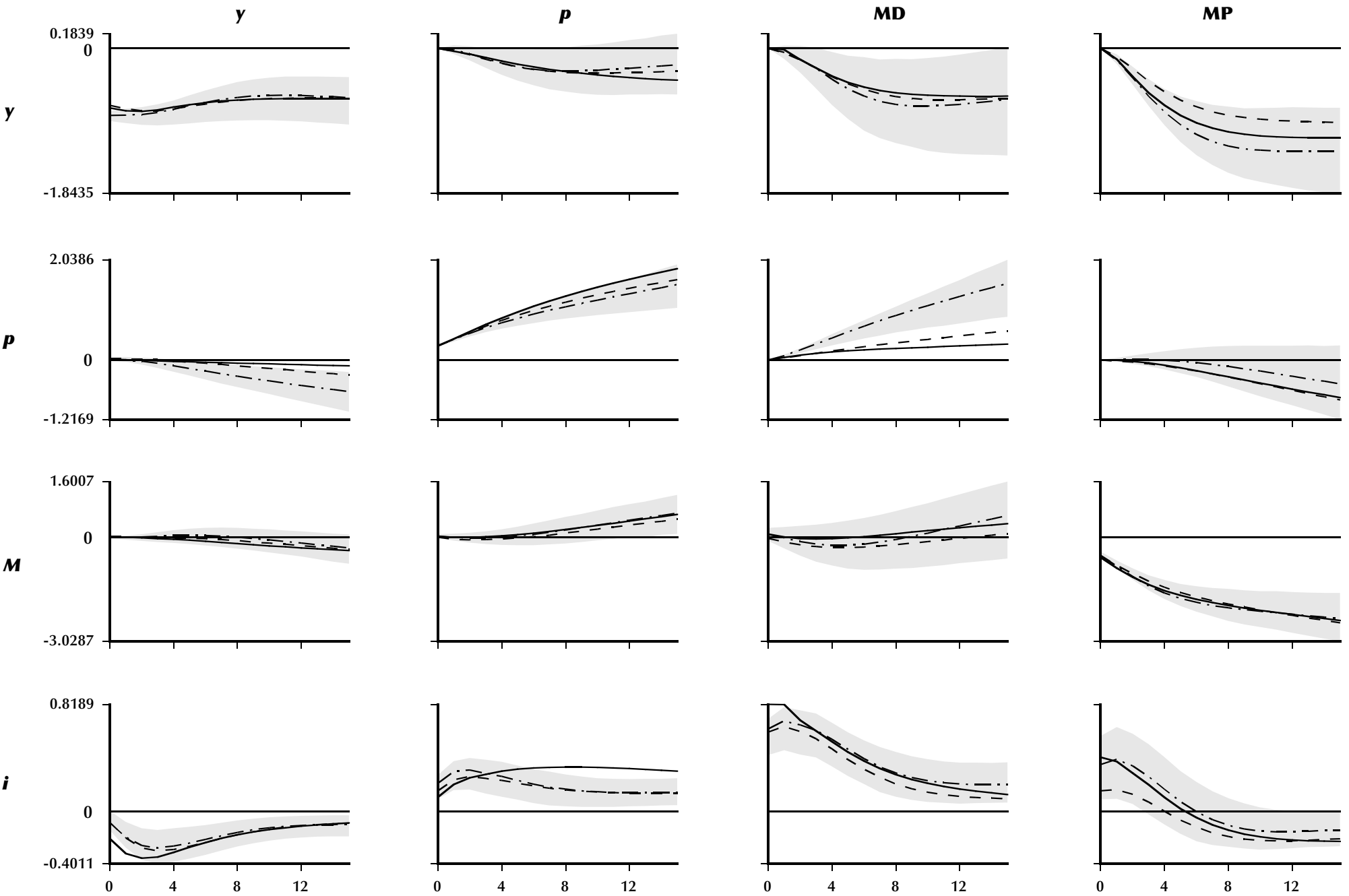

NOTE: The shaded region is a 68 percent error band associated with the model estimated from 1959:Q1 to 1979:Q3. 
some evidence in recent years that the output effects of policy shocks have weakened and the price effects have strengthened. In addition, much of the variance of the policy shocks over the entire sample derives from the 1979-82 period (note the smaller shock when that period is excluded). There is no evidence of a price puzzle: point estimates of price responses to a monetary contraction never rise, though the error band places some probability on a higher price path.

In contrast to the three-variable system, where both " $p$ " and " $y$ " shocks look like they shift aggregate demand, we now see distinct AS and AD disturbances. A " $y$ " shock moves output and prices in the same direction, as one would expect from AD, while a " $p$ " shock moves them in opposite directions, as would an AD disturbance. By separating the two kinds of aggregate shocks, the model allows a richer interpretation of policy behavior than can be gleaned from the model without money. When output and prices move together, policy responds to counteract the output effects. When output and prices move in opposite directions, policy tries to counteract the price effects. This pattern of policy responses is consistent with those found in the simple models with a Taylor rule (e.g., Figure 2), but they appear under very different identifying assumptions.

Some instability does show up in the model with money. The price effects of MD disturbances appear to be much weaker in models using recent data. And as in the three-variable system, the response of policy to a " $p$ " shock is stronger in recent years, though now we can interpret the " $p$ " shock as AS.

In contrast to the previous models, the fourvariable VAR has only one overidentifying restriction. When estimated from 1959-79, the data do not reject the model by any criterion: the test statistic is $\xi=1.04 ; \mathrm{SC}=4.43, \mathrm{AC}=2.0, p=.69$. Over the full sample there is more evidence against the model: $\xi=4.92 ; \mathrm{SC}=5.12, \mathrm{AC}=2.0, p=.03$.

Adding money alters many of the inferences from an identified VAR. Money appears to stabilize the system across time, it eliminates the anomalous price puzzle following MP shocks, and it helps to distinguish aggregate supply from non-monetary policy aggregate demand disturbances. The instability of M2 velocity since the early 1990s, which has motivated some researchers to eliminate money from their analyses, does not appear to raise difficulties for identifying monetary policy behavior. Neither does it interfere with the stability of pre- dictions about the dynamic impacts of exogenous shifts in policy.

\section{Implications of VAR Estimates}

NK analyses with simple policy rules consistently find that Federal Reserve behavior has been qualitatively different since 1979. Indeed, many authors attribute the superior performance of the U.S. economy over the past decade to superior policymaking. Central to this conclusion is that estimates of simple rules display substantial instability across time. We find no such instability in loosely identified VAR models with money. The contrast in our findings raises the possibility that some authors have overinterpreted the apparently shifting parameters in simple policy rules. The VAR literature, which does not attempt to reduce all policy behavior to two parameters, leads one to doubt the NK conclusions about policy. ${ }^{33}$

Views about the price puzzle in VARs have been influenced by Sims's (1992) argument. The Fed bases its choices on more information than small VARs contain, Sims argues, so what appears in a VAR to be an exogenous policy move is actually a response to extra-model information about aggregate supply disturbances. If this behavior is systematic, it can create a pattern of lower funds rates being followed by higher output and lower inflation. That view led to expanding VARs to include commodity prices, which serve as an "information variable" about supply developments, and thus diminishes or eliminates the price puzzle.

Hanson (2000a) questions the commodity price fix for the price puzzle. He shows that with Christiano, Eichenbaum, and Evans's (1999) recursive identification scheme, allowing the Fed to respond to current information in commodity prices does not resolve the price puzzle in data before 1979.34 We cannot discuss these arguments

\footnotetext{
33 Evidence from estimates of policy "reaction functions" supports the VAR findings. For example, Sims (1999) estimates a regime-switching equation describing the Fed's behavior. Although he finds that parameters describing systematic policy responses to the economy seem to shift across regimes, allowing for such shifts contributes little to the overall fit of the equation.

34 The price puzzle is not mere VAR esoterica. Taking Hanson's findings as background, Barth and Ramey (2000) propose that the price puzzle actually is no puzzle. Through the "cost channel," a monetary contraction reduces "working capital" and impacts both aggregate demand and aggregate supply. Under certain elasticities, the equilibrium price level should rise after a contraction. They offer industry-level support for the view that monetary contractions reduce output and raise pricewage ratios.
} 
in detail here. We are sympathetic to Hanson's view that the role of commodity prices in policy behavior is poorly understood and that they seem like a weak reed on which to rest identification of policy. We also believe that the role of commodity prices in helping to identify policy behavior has been overemphasized. In the four-variable identified VAR system, exogenous policy contractions never exhibit a price puzzle: the price level smoothly and strongly declines in all sample periods. These results obtain without the contrivance of commodity prices. Conditioning on commodity prices is neither necessary nor sufficient for resolving the price puzzle.

\section{CONCLUDING REMARKS}

NK research offers little advice on how, at the frequency of FOMC meetings, the Fed should behave. Few authors suggest the FOMC should mechanically obey the simple rule assumed in the theory. The most detailed discussion of the practical application of a simple rule comes from Taylor (1993a), who suggests that policymakers use it to compare recent FOMC decisions to the rule. And forecasts could include those of the funds rate using the rule. This analysis, Taylor suggests, could include a range of forecasts corresponding to different coefficients in the rule. This suggestion is close to how Leeper and Zha (2001) use an identified VAR to conduct counterfactual policy analysis. Jansson and Vredin (2000) propose blending the two approaches. From the standpoint of a practical policy analyst, therefore, the two approaches could be applied in similar ways.

Applying the estimated NK models to the kind of policy analysis Taylor suggests leads to a quandary. In all the NK models we estimated, the inflation effects of policy disturbances - or deviations from the estimated policy rule-are minimal. By extension, changes in policy parameters, if private decision makers view them as temporary, will also have trivial impacts on inflation. It is not at all clear what monetary policy can do to stabilize inflation in the estimated models.

We introduced the paper by noting that policy analysts face tough choices. Our results do nothing to make those choices easier. But an analyst who wishes to base policy advice on a stylized model and a simple policy rule should be aware of the pitfalls of doing so. While the stories are compelling, they also appear to be fragile. The tradeoff between simplicity and robustness is an unpleasant reality of policy analysis.

To be sure, our analysis did not exploit all the structure embodied in the canonical IS-AS-MP NK model. Cross-equation restrictions implied by dynamic behavior may help resolve some of the identification problems we highlighted. On the other hand, experience suggests that those dynamic restrictions are precisely the ones most at odds with data.

It is a mistake to regard this paper as running a horse race between stylized models with simple rules and identified VARs with complex dynamics and loose behavioral interpretations. Each has its place in policy advising. For a model to help inform policy choice, though, its identifying assumptions should be robust and its fit-both in-sample and out-of-sample-should be respectable.

We have argued, and demonstrated in several ways, that it is treacherous to draw inferences about policy effects solely from policy rules estimated in isolation from a complete macro model. System estimates of policy parameters can differ substantially from single-equation estimates. And system properties do not align well with values of particular policy parameters.

A central theme of the NK literature is that the Fed's performance in the Volcker-Greenspan era is far superior to the Fed's performance in earlier periods. This dramatic conclusion is based on the following: policy parameters have changed across two subperiods; NK models predict that policy in the recent period produces more stable economic outcomes. We find that from the perspective of system estimation, instability of policy rules does not appear to be a serious concern. Even if particular policy parameters are unstable, when the dynamics of behavior are well modeled, the equilibrium effects of policy are quite stable. And it's the equilibrium effects that concern policymakers.

At a minimum our results argue forcefully that the bold NK conclusion, that U.S. monetary policy has improved dramatically in the past 20 years, deserves more careful scrutiny.

\section{REFERENCES}

Barth, Marvin J. III and Ramey, Valerie A. "The Cost Channel of Monetary Transmission.” Unpublished manuscript, Board of Governors of the Federal Reserve System, April 2000 .

Bernanke, Ben S. and Mihov, Ilian. "Measuring Monetary Policy.” Quarterly Journal of Economics, August 1998, 113(3), pp. 869-902. 
and Woodford, Michael. "Inflation Forecasts and Monetary Policy." Journal of Money, Credit and Banking, 1997, 29(4, Part 2), 653-84.

Board of Governors of the Federal Reserve System. FOMC Minutes, 27-28 June 2000.

Bryant, Ralph C.; Hooper, Peter and Mann, Catherine L., eds. Evaluating Policy Regimes: New Research in Empirical Macroeconomics. Washington, DC: The Brookings Institution, 1993.

Canova, Fabio and Pires Pina, Joaquim. "Monetary Policy Misspecification in VAR Models." Unpublished manuscript, Universitat Pompeu Fabra, September 2000.

Christiano, Lawrence; Eichenbaum, Martin and Evans, Charles L. "Monetary Policy Shocks: What Have We Learned and to What End?," in John B. Taylor and Michael Woodford, eds., Handbook of Macroeconomics. Vol. 1A. Amsterdam: Elsevier Science, 1999, pp. 65-148.

Christiano, Lawrence J. " $\mathrm{P} *$ : Not the Inflation Forecaster's Holy Grail." Federal Reserve Bank of Minneapolis Quarterly Review, Fall 1989, 13(4), pp. 3-18.

Clarida, Richard; Gali, Jordi and Gertler, Mark. "The Science of Monetary Policy: A New Keynesian Perspective." Journal of Economic Literature, December 1999, 37(4), pp. 1661-707.

and "Monetary

Policy Rules and Macroeconomic Stability: Evidence and Some Theory." Quarterly Journal of Economics, February 2000, 115(1), pp. 147-80.

Cushman, David O. and Zha, Tao. "Identifying Monetary Policy in a Small Open Economy Under Flexible Exchange Rates." Journal of Monetary Economics, August 1997, 39(3), pp. 433-48.

Eichenbaum, Martin. "Comment on 'Interpreting the Macroeconomic Time Series Facts: The Effects of Monetary Policy'” European Economic Review, 1992, 36(5), pp. 1001-11.

Fuhrer, Jeffrey C. and Estrella, Arturo “Are 'Deep' Parameters Stable? The Lucas Critique as an Empirical Hypothesis." Unpublished paper, Federal Reserve Bank of Boston, September 1999

Gali, Jordi; Lopez-Salido, J. David and Valles, Javier. "Technology Shocks and Monetary Policy: Assessing the
Fed's Performance." Unpublished manuscript, Universitat Pompeu Fabra, May 2000.

Gordon, David B. and Leeper, Eric M. "The Dynamic Impacts of Monetary Policy: An Exercise in Tentative Identification." Journal of Political Economy, December 1994, 102(6), pp. 1228-47.

Gurley, John G. and Shaw, Edward S. Money in a Theory of Finance. Washington, DC: The Brookings Institution, 1960.

Hallman, Jeffrey J.; Porter, Richard D. and Small, David H. "Is the Price Level Tied to the M2 Monetary Aggregate in the Long Run?" American Economic Review, September 1991, 81(4), pp. 841-58.

Hanson, Michael S. "The 'Price Puzzle' Reconsidered." Unpublished manuscript, Wesleyan University, August 2000a.

Hanson, Michael S. "Varying Monetary Policy Regimes: A Vector Autoregressive Investigation." Unpublished manuscript, Wesleyan University, June 2000b.

Ireland, Peter N. "Money's Role in the Monetary Business Cycle." Unpublished manuscript, Boston College, April 2000 .

Jansson, Per and Vredin, Anders. "Forecast-Based Monetary Policy in Sweden 1992-1998." Unpublished manuscript, Sveriges Riksbank, August 2000.

Leeper, Eric M. 'Equilibria Under 'Active' and 'Passive' Monetary and Fiscal Policies." Journal of Monetary Economics, February 1991, 27(1), pp. 129-47.

Sims, Christopher A. and Zha, Tao. "What Does Monetary Policy Do?" Brookings Papers on Economic Activity, 1996, (2), pp. 1-63.

and Zha, Tao. "Modest Policy Interventions." Unpublished manuscript, Indiana University, January 2001

Levin, Andrew; Wieland, Volker and Williams, John C. "Robustness of Simple Monetary Policy Rules Under Model Uncertainty," in John B. Taylor, ed., Monetary Policy Rules. Chicago: University of Chicago Press, 1999, pp. 263-99.

McCallum, Bennett T. "Price Level Determinacy with an Interest Rate Policy Rule and Rational Expectations." Journal of Monetary Economics, 1981, 8(3), pp. 319-29. 
. "On Non-Uniqueness in Rational Expectations Models: An Attempt at Perspective." Journal of Monetary Economics, 1983, 11, pp. 139-68.

"Issues in the Design of Monetary Policy Rules," in John B. Taylor and Michael Woodford, eds., Handbook of Macroeconomics. Vol. 1C. Amsterdam: Elsevier Science, 1999, pp. 1483-530.

"Monetary Policy Analysis in Models Without Money." Unpublished manuscript, Carnegie-Mellon University, October 2000.

and Edward Nelson. "Performance of Operational Policy Rules in an Estimated Semiclassical Structural Model," in John B. Taylor, ed., Monetary Policy Rules. Chicago: University of Chicago Press, 1999, pp. 15-45.

Patinkin, Don. "The Indeterminacy of Absolute Prices in Classical Economic Theory.” Econometrica, 1949, 17(1), pp. 1-27.

Romer, David. "Keynesian Macroeconomics without the LM Curve.” Working Paper No. 7461, National Bureau for Economic Research, January 2000.

Rotemberg, Julio J. and Woodford, Michael. "An Optimization-Based Econometric Framework for the Evaluation of Monetary Policy," in Ben S. Bernanke and Julio J. Rotemberg, eds., NBER Macroeconomics Annual 1997. Cambridge, MA: MIT Press, 1997, pp. 297-346.

and "Interest Rate Rules in an Estimated Sticky Price Model," in John B. Taylor, ed., Monetary Policy Rules. Chicago: University of Chicago Press, 1999, pp. 57-119.

Sargent, Thomas J. Macroeconomic Theory. 2nd Ed. San Diego, CA: Academic Press, 1987 [original edition, 1979]. and Wallace, Neil. “'Rational' Expectations, the Optimal Monetary Instrument, and the Optimal Money Supply Rule.” Journal of Political Economy, April 1975, 83(2), pp. 241-54.

Sims, Christopher A. "A Rational Expectations Framework for Short-Run Policy Analysis," in William A. Barnett and Kenneth J. Singleton, eds., New Approaches to Monetary Economics. Cambridge: Cambridge University Press, 1987, pp. 293-308.

"Interpreting the Macroeconomic Time
Series Facts: The Effects of Monetary Policy." European Economic Review, June 1992, 36(5), pp. 975-1000.

"A Simple Model for Study of the Determination of the Price Level and the Interaction of Monetary and Fiscal Policy." Economic Theory, 1994, 4(3), pp. 381-99.

"Drifts and Breaks in Monetary Policy."

Unpublished manuscript, Princeton University, July 1999.

and Zha, Tao. "Bayesian Methods for Dynamic Multivariate Models.” International Economic Review, November 1998, 39(4), pp. 949-68.

and "Error Bands for Impulse Responses.” Econometrica, September 1999, 67(5), pp. 1113-55.

Stiglitz, Joseph E. and Walsh, Carl. Principles of Macroeconomics. 3rd Ed. New York: W.W. Norton, 2000.

Taylor, John B. "Discretion Versus Policy Rules in Practice." Carnegie-Rochester Conference Series on Public Policy, December 1993a, 39, 195-214.

Macroeconomic Policy in a World Economy: From Econometric Design to Practical Operation. New York: W.W. Norton, 1993b.

"A Historical Analysis of Monetary Policy Rules, " in John B. Taylor, ed., Monetary Policy Rules. Chicago: University of Chicago Press, 1999a, pp. 319-41.

"The Robustness and Efficiency of Monetary Policy Rules as Guidelines for Interest Rate Setting by the European Central Bank." Journal of Monetary Economics, June 1999b, 43(3), pp. 655-79.

Waggoner, Daniel F. and Zha, Tao. "A Gibb's Sampler for Structural Vector Autoregressions.” Unpublished manuscript, Federal Reserve Bank of Atlanta, September 2000 .

Woodford, Michael. "Doing Without Money: Controlling Inflation in a Post-Monetary World." Review of Economic Dynamics, January 1998, 1(1), pp. 173-219.

Woodford, Michael."Inflation Stabilization and Welfare," in Interest and Prices, Chap. 6. Unpublished manuscript, 1999a.

Woodford, Michael. "Optimal Monetary Policy Inertia." NBER Working Paper No. 7261, July 1999b. 